\title{
Loss of RAD-23 Protects Against Models of Motor Neuron Disease by Enhancing Mutant Protein Clearance
}

\author{
Angela M. Jablonski, ${ }^{1}$ Todd Lamitina, ${ }^{4}$ Nicole F. Liachko, ${ }^{5}{ }^{\oplus}$ Mariangela Sabatella, ${ }^{6}$ Jiayin Lu, ${ }^{7}$ Lei Zhang, ${ }^{2}$ \\ Lyle W. Ostrow, ${ }^{8}$ Preetika Gupta, ${ }^{1}$ Chia-Yen Wu, ${ }^{2}$ Shachee Doshi, ${ }^{1}$ Jelena Mojsilovic-Petrovic, ${ }^{2}$ Hannes Lans, ${ }^{6}$ \\ ๑) Jiou Wang, ${ }^{7}$ Brian Kraemer, ${ }^{6}$ and Robert G. Kalb ${ }^{2,3}$ \\ ${ }^{1}$ Department of Neuroscience, Perelman School of Medicine, University of Pennsylvania, Philadelphia, Pennsylvania 19104, ${ }^{2}$ Department of Pediatrics, \\ Division of Neurology, Research Institute, Children's Hospital of Philadelphia, Philadelphia, Pennsylvania 19104, ${ }^{3}$ Department of Neurology, Perelman \\ School of Medicine, University of Pennsylvania, Philadelphia, Pennsylvania 19104, ${ }^{4}$ Department of Pediatrics and Cell Biology, University of Pittsburgh \\ Medical Center, Pittsburgh, Pennsylvania 15213, ${ }^{5}$ Geriatric Research Education and Clinical Center, Veterans Affairs Puget Sound Health Care System, \\ Department of Medicine, University of Washington, Seattle, Washington 98195, ${ }^{6}$ Department of Genetics, Erasmus Medical Centre, Cancer Genomics \\ Institute, Rotterdam 3015 CN, The Netherlands, ${ }^{7}$ Department of Biochemistry and Molecular Biology, Bloomberg School of Public Health, Johns Hopkins \\ University School of Medicine, Baltimore, Maryland 21205, and ${ }^{8}$ Department of Neurology, Johns Hopkins University School of Medicine, Baltimore, \\ Maryland 21205
}

Misfolded proteins accumulate and aggregate in neurodegenerative disease. The existence of these deposits reflects a derangement in the protein homeostasis machinery. Using a candidate gene screen, we report that loss of RAD-23 protects against the toxicity of proteins known to aggregate in amyotrophic lateral sclerosis. Loss of RAD-23 suppresses the locomotor deficit of Caenorhabditis elegans engineered to express mutTDP-43 or mutSOD1 and also protects against aging and proteotoxic insults. Knockdown of RAD-23 is further neuroprotective against the toxicity of SOD1 and TDP-43 expression in mammalian neurons. Biochemical investigation indicates that RAD-23 modifies mutTDP-43 and mutSOD1 abundance, solubility, and turnover in association with altering the ubiquitination status of these substrates. In human amyotrophic lateral sclerosis spinal cord, we find that RAD-23 abundance is increased and RAD-23 is mislocalized within motor neurons. We propose a novel pathophysiological function for RAD-23 in the stabilization of mutated proteins that cause neurodegeneration.

Key words: aging; ALS; motor neuron disease; neurodegeneration; proteotoxicity; RAD-23

Significance Statement

In this work, we identify RAD-23, a component of the protein homeostasis network and nucleotide excision repair pathway, as a modifier of the toxicity of two disease-causing, misfolding-prone proteins, SOD1 and TDP-43. Reducing the abundance of RAD-23 accelerates the degradation of mutant SOD1 and TDP-43 and reduces the cellular content of the toxic species. The existence of endogenous proteins that act as "anti-chaperones" uncovers new and general targets for therapeutic intervention.

\section{Introduction}

Amyotrophic lateral sclerosis (ALS) is a multifactorial, adult onset motor neuron disease that causes death of the upper and lower motor neurons, leading to muscle denervation and eventual paralysis.

\footnotetext{
Received Feb. 16, 2015; revised Aug. 31, 2015; accepted Sept. 8, 2015.

Author contributions: A.M.J., T.L., N.F.L., M.S., J.L., L.Z., L.W.O., C.-Y.W., H.L., J.W., B.K., and R.G.K. designed research; A.M.J., T.L., N.F.L., M.S., J.L., L.Z., P.G., C.-Y.W., S.D., H.L., J.W., and B.K. performed research;A.M.J., L.W.O., and J.M.-P. contributed unpublished reagents/analytic tools; A.M.J., T.L., N.F.L., M.S., J.L., P.G., C.Y.W., S.D., H.L., J.W., B.K., and R.G.K. analyzed data; A.M.J. and R.G.K. wrote the paper.

This work was supported by NIH Grants R01-NS052325 and R21-NS077909 to R.G.K., F31-NS07726 to A.M.J., and FP7 Marie Curie International Training Network Address 316390 to M.S. The RAD-23 fosmid was obtained from the C. elegans Transgene $0 \mathrm{me}$ project. Some strains were provided by the Caenorhabditis Genetics Center, which is funded by National Institutes of Health Office of Research Infrastructure Programs P40-0D010440, and the National Bioresource Project for the Nematode. We thank Ulrich Hartl for the CPY*-GFP plasmid; Steven Grossman for the RAD-23
}

Approximately $90 \%$ of cases of ALS are sporadic, and the remaining cases are caused by single gene mutations (Rothstein, 2009). The pathophysiology of ALS has been linked to oxidative stress, excitotoxicity, impaired protein homeostasis, and defects in RNA biology (Cleveland and Rothstein, 2001; Ling et al., 2013).

plasmids; Johns Ravits and Jeff Rothstein for providing human tissue; Maria Lim, Elizabeth Morton, Zissimos Mourelatos, and Predrag Krajacic for assistance; the Target ALS Human Postmortem Tissue Core for providing postmortem tissue samples; and Harry Ischiropolous, Kelly Jordan-Sciutto, Alice Chen-Plotkin, and Raymond Roos for guidance and helpful discussion.

The authors declare no competing financial interests.

Correspondence should be addressed to Dr. Robert G. Kalb, Research Institute, Children's Hospital of Philadelphia, 3615 Civic Center Blvd, Philadelphia, PA 19104. E-mail: kalb@email.chop.edu.

DOI:10.1523/JNEUROSCI.0642-15.2015

Copyright $\odot 2015$ the authors $\quad 0270-6474 / 15 / 3514286-21 \$ 15.00 / 0$ 
Table 1. Mammalian ERAD genes and their predicted orthologs in C. elegans ${ }^{a}$

\begin{tabular}{|c|c|c|c|c|c|}
\hline Mammalian gene & Worm gene & Putative function & Mutant available & Mutation description & Comment \\
\hline EDEM1 & C47E12.3 & Glycosylhydrolase-47 family & ok2898 & $378 \mathrm{bp}$ deletion & \\
\hline EDEM2 & $\mathrm{F} 10 \mathrm{C} 2.5$ & Glycosylhydrolase-47 family & $\operatorname{tm} 6057$ & 563 bp deletion & Affects $>1$ gene \\
\hline OS9 & Y105E8A0.2 & $\begin{array}{l}\text { Inspects client proteins for terminal } \alpha 1,6 \text { linked } \\
\text { mannose }\end{array}$ & $\operatorname{tm} 5511$ & 517 bp deletion & \\
\hline TEB4 & F55A3.1 & D0A10 ligase component & $g k 218188$ & Introduces stop codon mid-gene & \\
\hline Erasin & ZK353.8 & D0A10 ligase component & $\operatorname{tm} 3247$ & 323 bp deletion & Tested \\
\hline HRD1 & F55A11.3 & E3 ubiquitin ligase & $\operatorname{tm} 1743$ & 473 bp deletion +38 bp insertion & \\
\hline HRDL-1 & F26E4.11 & E3 ubiquitin ligase & $g k 28$ & 1981 bp deletion & \\
\hline Derlin-1 & F25D7.1 & HRD ligase component; retrotranslocon & $\operatorname{tm} 2839$ & 224 bp deletion & Tested \\
\hline Derlin-2/Derlin-3 & R151.6 & HRD ligase component & $\operatorname{tm} 5861$ & 499 bp deletion & \\
\hline RNF5 & $\mathrm{C} 16 \mathrm{C} 10.7$ & RMA1 ligase & $\operatorname{tm} 794$ & 647 bp deletion & \\
\hline p97 (VCP) & C06A1.1 & Extractor & $\operatorname{tm} 544$ & 688 bp deletion & Tested \\
\hline p97 (VCP) & C $41 C 4.8$ & Extractor & $\operatorname{tm} 659$ & 639 bp deletion & Tested \\
\hline UFD-2 & T05H10.5 & p97 (VCP) cofactor & $\operatorname{tm} 1380$ & 915 bp deletion & Tested \\
\hline UFD-3 & $\mathrm{C} 05 \mathrm{C} 10.6$ & p97 (VCP) cofactor & $\operatorname{tm} 2915$ & 747 bp deletion & Tested \\
\hline RAD-23 & ZK20.3 & Proteasome adaptor & $\operatorname{tm} 3690 ; \operatorname{tm} 2595$ & $\begin{array}{l}432 \text { bp deletion; } 677 \text { bp deletion }+ \\
28 \text { bp insertion }\end{array}$ & Tested \\
\hline UBQLN-2 & $\mathrm{F} 15 \mathrm{C} 11.2 \mathrm{a}$ & Proteasome adaptor & $\operatorname{tm} 1574$ & 755 bp deletion & Tested \\
\hline
\end{tabular}

${ }^{a}$ There are $\sim 25$ ERAD genes predicted to be conserved in C. elegans. Of these, viable mutants are available in many and were used in a candidate gene approach to identify novel modifiers of mutTDP-43 toxicity in C. elegans. Several conserved mammalian ERAD genes in the nematode have no mutants available at the time of this study, including the following: Ubc14 (Y87G2A0.9); Ube2K (F40G9.3); Ube2G (F58A4.10.1); ERManl (T03G11.4); Npl4 (F59E12.5); Ufd-1 (F19B6.2a); Ube2J1/Ube2J2 (D1022.1a); and Ube2G2 (Y87G2A0.9).

Some of the earliest events seen in rodent ALS models include the accumulation of misfolded proteins, ER stress, and activation of the unfolded protein response (Kikuchi et al., 2006; Nagata et al., 2007; Saxena et al., 2009; Wang et al., 2011; Walker et al., 2013; Filézac de L'Etang et al., 2015). Exacerbated ER stress has also been found in forms of sporadic ALS (sALS) (Atkin et al., 2008). One way cells deal with ER stress, linked to the accumulation of misfolded proteins in the ER lumen, is by ER-associated degradation (ERAD). In this process, terminally misfolded ER lumen proteins are cleared from the ER through a multistep process for degradation by the 26 S proteasome (Vembar and Brodsky, 2008). Positive and negative regulators of this process are known to exist (Rumpf and Jentsch, 2006), and several components of the ERAD pathway have been identified as being mutated in forms of familial ALS (fALS) (Johnson et al., 2010; Deng et al., 2011).

We hypothesized that components of ERAD might be modifiers of ALS. To test this, we used a Caenorhabditis elegans model of ALS in which mutant (M337V) TDP-43 (mutTDP-43) is expressed in the nervous system (Liachko et al., 2010). Using a candidate gene forward genetics approach (Table 1), we asked whether loss-of-function alleles (mutants) of ERAD components influenced the uncoordinated phenotype (locomotor deficit) of mutTDP-43 animals. Among the modifiers, we found that a lossof-function mutation of rad-23 suppressed the locomotor deficit of mutTDP-43.

RAD-23 has two known functions: (1) it can bind ubiquitinated substrates and the proteasome to aid in clearance of certain substrates (Chen and Madura, 2006); and (2) it assists in nucleotide excision repair (NER) initiation to correct distorted double helices resulting from DNA damage (Dantuma et al., 2009; Bergink et al., 2012). We demonstrate that loss of rad-23 has a beneficial effect in models of ALS in C. elegans and mammalian neurons, and this effect is linked to improved protein homeostasis and the clearance of ALS-causing proteins by the loss of RAD-23.

The pathophysiological relevance of our work to human disease is suggested by changes in RAD-23 abundance and cellular distribution in ALS spinal cord samples. We propose that native RAD-23 acts as an "anti-chaperone" to stabilize and prevent the turnover of misfolding-prone proteins that cause ALS. These data raise the possibility that targeted reduction of RAD-23 could have therapeutic utility in ALS.

\section{Materials and Methods}

Antibodies. The following antibodies were used in this study: hR23A (Abcam ab55725), hR23B (Abcam ab88053), TDP-43 (Abcam ab57105 for immunoblotting), myc (Cell Signaling Technology 2276), hSOD1 (Abcam ab52950), V5 (EMD Millipore ab3792), GFP (Sigma G1546), $\beta$-actin (Sigma A2066), ubiquitin (Dako Z0458), SMI32 (Invitrogen), biotinylated goat anti-mouse IgG (Vector Laboratories BA-9200), antimouse and anti-rabbit AlexaFluor antibodies (Invitrogen), and antimouse and anti-rabbit IRDye antibodies (Li-Cor).

C. elegans strains. All animals were grown on Nematode Growth Media (NGM) plates seeded with Escherichia coli OP50 and maintained at $20^{\circ} \mathrm{C}$ (Brenner, 1974). The following C. elegans strains were obtained from the C. elegans Genetic Center and National Bioresource Project for the Nematode: the N2 Bristol strain, rad-23 (tm3690 and tm2595), ufd-3 (tm2915), ufd-2 (tm1380), cdc-48.1 (tm544), cdc-48.2 (tm659), ubxn-4 (tm3247), and ubql-1 (tm1574). All strains were backcrossed 5 generations to ancestral N2 (Table 2). The hSOD1-expressing lines $\left(\mathrm{P}_{\text {snb- } 1}:: W T\right.$ SOD1-YFP and $\mathrm{P}_{\text {snb-1 }}:$ G85R SOD1-YFP) and hTDP-43-expressing lines $\left(\mathrm{P}_{\text {snb-1 }}:: W T\right.$ TDP-43 and $\mathrm{P}_{\text {snb- } 1}:: \mathrm{M} 337 \mathrm{~V}$ TDP-43) were generated as described previously (J. Wang et al., 2009 and Liachko et al., 2010, respectively). Compound mutant strains, consisting of the mutation/allele and the TDP-43 or SOD1 transgene, were confirmed by fluorescence and the PCR using primers for the allele (Table 3). The G85R; sid-1 (pk3321); $\mathrm{P}_{\text {unc-119: }}: \mathrm{SID}-1$ strain was created as previously described (Calixto et al., 2010; Lim et al., 2012). The RAD-23 rescue lines were created using Gateway Cloning (Invitrogen). Briefly, RAD-23 genomic DNA was amplified from DNA isolated from wild-type (WT) C. elegans and cloned into the pDonR221 entry vector. The LR reaction was then performed with the pCFJ150 destination vector, $\mathrm{P}_{\text {unc-119 }}$ entry clone (nervous system expression) (first position), the RAD-23 entry clone (second position), and unc-54 3'UTR entry clone (third position). The resulting vector was confirmed by Sanger sequencing and injected into the gonads of either mutTDP-43 or mutTDP-43; rad-23 $(\mathrm{tm} 3690)$ animals until 3 stable lines were created. The RAD-23 expression construct was coinjected with a $\mathrm{P}_{\text {unc1119 }}:$ GFP coinjection marker. A list of all strains used in this study can be found in Table 2 .

Locomotor assays. C. elegans locomotor assays were performed as a swimming assay in a drop of M9 buffer $\left(22 \mathrm{~mm} \mathrm{KH}_{2} \mathrm{PO}_{4}, 42 \mathrm{~mm}\right.$ $\mathrm{Na}_{2} \mathrm{HPO}_{4}, 86 \mathrm{~mm} \mathrm{NaCl}$ ) on the surface of an agar plate. For each assay, 15-25 worms were allowed to lay eggs for $4 \mathrm{~h}$. Behavior was blindly 
Table 2. A list of the C. elegans strains used in this study and their corresponding information $^{a}$

\begin{tabular}{|c|c|c|}
\hline Strain name & Coinjection marker & Description \\
\hline RK65 & NA & $\operatorname{tm} 3690$ \\
\hline RK66 & NA & $\operatorname{tm} 2595$ \\
\hline RK67 & NA & mutTDP-43 (M337V); RK65 (tm3690) \\
\hline RK68 & NA & mutTDP-43 (M337V); RK66 (tm2595) \\
\hline RK69 & NA & wtTDP-43; RK65 (tm3690) \\
\hline RK70 & NA & wtTDP-43; RK66 (tm2595) \\
\hline RK71 & NA & mutS0D (G85R); RK65 (tm3690) \\
\hline RK72 & NA & mutS0D (G85R); RK66 (tm2595) \\
\hline RK73 & NA & wtS0D; RK65 (tm3690) \\
\hline RK74 & NA & wtS0D; RK65 (tm3690) \\
\hline RK75 & NA & mutTDP-43 (M337V);png-1 (cy9) \\
\hline RK76 & NA & mutTDP-43 (M337V); xpa-1 (ok698) \\
\hline RK77 & NA & mutTDP-43 (M337V); csb-1 (tm2073) \\
\hline RK78 & NA & mutTDP-43 (M337V); ercc-1 (ok2335) \\
\hline RK79(rkEx1) & None & $\begin{array}{l}P_{\text {RAD23 }}: \text { RAD23::GFP } \\
\text { (fosmid injected at } 5 \mathrm{ng} / \mu \mathrm{l} \text { ) }\end{array}$ \\
\hline RK80 & NA & $\operatorname{tm} 2909$ \\
\hline RK81 & NA & $\operatorname{tm} 1574$ \\
\hline RK82 & NA & $\operatorname{tm} 2915$ \\
\hline RK84 & NA & $\operatorname{tm} 544$ \\
\hline RK85 & NA & $\operatorname{tm} 3247$ \\
\hline RK86 & NA & mutTDP-43 (M337V); RK81 (tm1574) \\
\hline RK87 & NA & mutS0D (G85R); RK81 (tm1574) \\
\hline RK88 & NA & mutTDP-43 (M337V); RK82 (tm2915) \\
\hline RK91 & NA & mutTDP-43 (M337V); RK84 (tm544) \\
\hline RK92 & NA & mutTDP-43 (M337V); RK85 (tm3247) \\
\hline RK93 & NA & $\begin{array}{l}\text { RK88; RK65 } \\
\text { mutTDP-43 (M337V); tm2915; tm3690 }\end{array}$ \\
\hline RK94 & NA & mutTDP-43 (M337V); tm1380 \\
\hline RK95 & NA & $\begin{array}{l}\text { RK94; RK65 } \\
\text { mutTDP-43 (M337V); tm1380; tm3690 }\end{array}$ \\
\hline RK96 & NA & $\operatorname{tm} 659$ \\
\hline RK97 & NA & mutTDP-43 (M337V); tm659 \\
\hline OG695(drEx230) & $\begin{array}{l}P_{\text {unc-119::GFP }} \\
\text { (injected at } \\
100 \mathrm{ng} / \mu \mathrm{l} \text { ) }\end{array}$ & $\begin{array}{l}\text { mutTDP-43 (M337V); } \\
P_{\text {unc-119::RAD23::Unc54 3' UTR-LINE1 }} \\
\text { (construct injected at } 30 \mathrm{ng} / \mu \mathrm{l} \text { ) }\end{array}$ \\
\hline OG696(drEx231) & $\begin{array}{l}P_{\text {unc-119::GFP }} \\
\text { (injected at } \\
100 \mathrm{ng} / \mu \mathrm{l} \text { ) }\end{array}$ & $\begin{array}{l}\text { mutTDP-43 (M337V); } \\
P_{\text {unc-119::RAD23::unc54 3'UTR-LINE2 }} \\
\text { (construct injected at } 30 \mathrm{ng} / \mu \mathrm{l} \text { ) }\end{array}$ \\
\hline OG697(drEx232) & $\begin{array}{l}P_{\text {unc-119::GFP }} \\
\text { (injected at } \\
100 \mathrm{ng} / \mu \mathrm{l} \text { ) }\end{array}$ & $\begin{array}{l}\text { mutTDP-43 (M337V); } \\
P_{\text {unc-119::RAD23::unc54 3'UTR-LINE3 }} \\
\text { (construct injected at } 30 \mathrm{ng} / \mu \mathrm{l} \text { ) }\end{array}$ \\
\hline OG692(drEx227) & $\begin{array}{l}P_{\text {unc-119:.GFP }} \\
\text { (injected at } \\
100 \mathrm{ng} / \mu \mathrm{l} \text { ) }\end{array}$ & $\begin{array}{l}\text { mutTDP-43 (M337V); rad23 (tm3690); } \\
P_{\text {unc-119::RAD23::.unc54 3' UTR-LINE1 }} \\
\text { (construct injected at } 30 \mathrm{ng} / \mu \mathrm{l} \text { ) }\end{array}$ \\
\hline OG693(drEx228) & $\begin{array}{l}P_{\text {unc-119:.GFP }} \\
\text { (injected at } \\
100 \mathrm{ng} / \mu \mathrm{l} \text { ) }\end{array}$ & $\begin{array}{l}\text { mutTDP-43 (M337V); rad23 (tm3690); } \\
P_{\text {unc-119::RAD23::.unc54 3' UTR-LINE2 }} \\
\text { (construct injected at } 30 \mathrm{ng} / \mu \mathrm{l} \text { ) }\end{array}$ \\
\hline OG694(drEx229) & $\begin{array}{l}P_{\text {unc-119::GFP }} \\
\text { (injected at } \\
100 \mathrm{ng} / \mu \mathrm{l} \text { ) }\end{array}$ & $\begin{array}{l}\text { mutTDP-43 (M337V); rad23 (tm3690); } \\
P_{\text {unc-119::RAD23::unc54 3'UTR-LINE3 }} \\
\text { (injected at } 30 \mathrm{ng} / \mu \mathrm{l} \text { ) }\end{array}$ \\
\hline
\end{tabular}

${ }^{a}$ All strains used in this set of studies were backcrossed to ancestral N2 5 times. NA, Not applicable.

recorded at the young adult stage ( $24 \mathrm{~h}$ after L4) for $30 \mathrm{~s}$ on a video camera attached to a Zeiss Steml SV11 dissecting scope. Five replicates containing 7-10 animals per group were tested. Videos were tracked and then analyzed using the Parallel WormTracker (http://wormsense. stanford.edu/tracker; Miriam Goodman; Stanford University, Palo Alto, CA) script on MATLAB (The MathWorks) to determine the average speed (millimeters per second). Each experiment was completed three independent times on different days. One representative experiment is shown unless otherwise indicated.

RNAi knockdown in C. elegans. Each RNAi (RNA Interference) colony was grown overnight in Luria broth containing ampicillin $(50 \mu \mathrm{g} / \mathrm{ml})$, and $200 \mu \mathrm{l}$ was seeded onto NGM plates containing isopropylthiogalac-
Table 3. List of primers used in genotyping C. elegans strains ${ }^{a}$

\begin{tabular}{|c|c|c|}
\hline Gene & Allele & Primer $\left(5^{\prime}-3^{\prime}\right)$ (upper/lower) \\
\hline $\mathrm{rad}-23$ & $\operatorname{tm} 2595$ & $\begin{array}{l}\text { caggatggttttgtccgttac } \\
\text { acatgcgaaataagcctccac }\end{array}$ \\
\hline & $\operatorname{tm} 3690$ & $\begin{array}{l}\text { aaggcgatgaatacacattcttgg } \\
\text { atcgataacctggatgagggatgg }\end{array}$ \\
\hline ufd-3 & $\operatorname{tm} 2915$ & $\begin{array}{l}\text { ttttgggcaatagatggaggc } \\
\text { aaatgcccgagcttctgg }\end{array}$ \\
\hline ufd-2 & $\operatorname{tm} 1380$ & $\begin{array}{l}\text { tacttggagagccaacttcgc } \\
\text { acaaaatccatagaagatgce }\end{array}$ \\
\hline$c d c-48.1$ & $\operatorname{tm} 544$ & $\begin{array}{l}\text { ttccacgtggtggcttgatac } \\
\text { aaccegcattcacgtgctc }\end{array}$ \\
\hline derlin-1 & $\operatorname{tm} 2909$ & $\begin{array}{l}\text { ttccatcttgaccgtgaatacc } \\
\text { atatctacttccttctcgaaccg }\end{array}$ \\
\hline$u b x n-4$ & $\operatorname{tm} 3247$ & $\begin{array}{l}\text { acatgtttgtcggectctcg } \\
\text { aactttcaacacctagtcc }\end{array}$ \\
\hline$u b q l-1$ & $\operatorname{tm} 1574$ & $\begin{array}{l}\text { gcatattgaagctcgcgcg } \\
\text { acggtgatttcacgtgaac }\end{array}$ \\
\hline xpa-1 & ok698 & $\begin{array}{l}\text { gaccgttgagcttattgcag } \\
\text { taacttgttgtggccatgcg }\end{array}$ \\
\hline$c s b-1$ & ok2335 & $\begin{array}{l}\text { gaagactgatcatcggagcg } \\
\text { ggctgggggattcaaattat }\end{array}$ \\
\hline ercc-1 & $\operatorname{tm} 2073$ & $\begin{array}{l}\text { ttcggtgtcgtctatctcag } \\
\text { tttttgcgacatccctggcg }\end{array}$ \\
\hline png-1 & $c y 9$ & $\begin{array}{l}\text { gtcgataattttaccgaattttccac } \\
\text { tatctccaagtgacgtcaaccac }\end{array}$ \\
\hline
\end{tabular}

$\overline{{ }^{a} \text { All of the primers used in genotyping the C. elegans strains used in this study. Further information is available upon }}$ request.

toside ( $1 \mathrm{~mm}$ ) to induce dsRNA expression. The RNAi clone for rad-23 was generated as described previously in the Ahringer library (Fraser et al., 2000), and its correctness was confirmed by sequencing. For locomotor experiments, staged L4 animals were placed on RNAi plates overnight. On the next day, young adult $C$. elegans were transferred to a fresh RNAi plate and allowed to lay eggs for 4-6 h. Progeny were subsequently tested at the young adult $(\mathrm{L} 4+1 \mathrm{~d})$ stage for locomotor activity as described above. For RNAi experiments, the average of three independent experiments is shown.

Tunicamycin lifespan assay. WT (N2 Bristol strain) or rad-23 (tm3690) C. elegans were allowed to lay eggs on NGM plates for 4-6 h ("egg dropping"). At the young adult stage, 100 animals were placed on NGM plates supplemented with either vehicle (DMSO) or tunicamycin (Sigma T7765; $5 \mu \mathrm{g} / \mathrm{ml}$ ). NGM plates were all seeded with OP50, and the final concentration of DMSO in the plates did not exceed $0.2 \%$. Animals were transferred to a fresh plate every day and scored for survival by response to light touch. Bagging worms or worms with a vulva explosion phenotype were excluded from the analysis. All assays were completed blind to genotype.

Heat shock lifespan assay. For heat shock assay, WT (N2 Bristol strain) or rad-23 (tm3690) animals were allowed to lay eggs on NGM plates for $4-6 \mathrm{~h}$. At the L4 stage, $\sim 50$ animals per group were transferred to a fresh plate. At the young adult $(\mathrm{L} 4+1 \mathrm{~d})$ stage, NGM plates were fully submerged into a water bath in a plastic bag at $34^{\circ} \mathrm{C}$. Plates were removed briefly every hour so that animals could be scored for survival by response to a light touch. Bagging worms or worms with a vulva explosion phenotype were excluded from the analysis. All analyses were performed blind to genotype.

Biomechanical profiling software. We used a MATLAB-based image analysis program to quantify the biomechanics of $C$. elegans swimming behavior as previously described (Sznitman et al., 2010; Krajacic et al., 2012). WT (N2 Bristol strain) or rad-23 (tm3690) animals were allowed to lay eggs for $4-6 \mathrm{~h}$. Worms were staged at L4 based on the transparency of the vulva mark. At L4 and for $5 \mathrm{~d}$ after L4, recordings were taken ( $\geq 10$ /group at each time point). Briefly, 1-3 animals were transferred into a $50 \mu \mathrm{l}$ drop of M9 buffer in the recording chamber and, after $2 \mathrm{~min}$ of acclimation, were covered with a coverslip. Recordings of $4-15 \mathrm{~s}$ of a single animal in the chamber were obtained using standard bright-field microscopy at 26 frames per second. For each recording of a single ani- 
mal, worm curvature was captured and plotted over time. Worm speed, force, and power calculation were performed in MATLAB (The MathWorks) (Krajacic et al., 2012). All analyses were performed blind to genotype.

UV sensitivity assay. UV survival experiments were performed as previously described (Lans et al., 2010). For each genotype, 16-25 C. elegans young adults were irradiated at the indicated UV-B dose and, following $24 \mathrm{~h}$ of recovery, transferred to $4-5$ NGM plates to lay eggs for a 2-3 h period. Survival of progeny was later assessed.

Fluorescence recovery after photobleaching (FRAP) assay. Animals were immobilized with 10 mM levamisole and examined with a Leica DMI3000 B confocal microscope. Experiments were performed as described by L. Wang et al. (2009).

Recombinant HSV constructs. $h R 23 A$ and $h R 23 B$ miRNA was designed against the target sequences, 5'-CCAGAACATGCGGCAAGTGAT-3' and $5^{\prime}$-TGGTAACTGAGATCATGTCAA- $3^{\prime}$, respectively. Primers were annealed and cloned into the p1006(+) vector backbone using the BspE1 and FseI restriction sites. The p1006(+) amplicon plasmids were then used to generate recombinant HSV as described previously (Neve et al., 1997). The titer of virus used in these experiments was $-3-5 \times 10^{7}$ plaque-forming units $/ \mathrm{ml}$.

Cell culture. Mixed spinal cord neuron cultures were prepared as described previously (Mojsilovic-Petrovic et al., 2006). Briefly, an astrocyte feeder layer was prepared from the cortex of newborn Sprague Dawley rat pups (postnatal day $2[\mathrm{P} 2]$ ) and grown to $\sim 80 \%$ confluency. Subsequently, dissociated embryonic day 15 (E15) spinal cord neurons were added. One to two days later, AraC (5 mM) (catalog \#C6645; Sigma) was added for $24 \mathrm{~h}$ to arrest astrocyte proliferation. Cultures were maintained in glia-conditioned medium supplemented with the following trophic factors $(1.0 \mathrm{ng} / \mathrm{ml}$ each): human neurotrophin-3, human neurotrophin-4, human brain-derived neurotrophic factor, and rat ciliary neurotrophic factor (Alomone Labs). Half of the culture medium was replaced on a biweekly basis.

HEK293 (Human Embryonic Kidney 293) cells were grown in DMEM (Invitrogen) supplemented with 10\% FBS (Sigma) and 1\% Pen-Strep (Sigma). WT, hR23A ${ }^{-1-}$, and $\mathrm{hR} 23 \mathrm{~B}^{-/-}$mouse embryonic fibroblasts (MEFs) were maintained in DMEM with GlutaMax and high glutamine (Invitrogen) supplemented with 10\% FBS (Sigma) and 1\% Pen-Strep (Sigma). MEFs were created as previously described (Okuda et al., 2004).

Transfections. Cells were transfected using Lipofectamine 2000 (Invitrogen) in antibiotic-free medium once cells reached $\sim 75 \%$ confluency. Media was replaced after $24 \mathrm{~h}$. Experiments were performed $48 \mathrm{~h}$ after transfection unless otherwise indicated.

Cychloheximide (CHX) assays. When cells were 75\% confluent, the HEK293 cells were cotransfected (Lipofectamine 2000; Invitrogen) with indicated TDP-43 or SOD1 expression constructs and a control or RAD-23 (hR23A or hR23B) miRNA using Lipofectamine 2000 (Invitrogen) in antibiotic-free media. MEFs were transfected (Lipofectamine 2000; Invitrogen) with TDP-43 expression construct and LacZ or respective hR23A or hR23B cDNA if indicated. For studies in mixed spinal cord cultures, neurons were infected with HSV to express human versions of wtSOD1, mutSOD1, wtTDP-43, or mutTDP-43 alongside an HSV expressing a control, hR23A, or hR23B miRNA. After $24 \mathrm{~h}$, cells were replated in their standard media at equal densities, and HEK293 cells or MEFs were replated in duplicate or triplicate as needed. At $24 \mathrm{~h}$ later, the media was removed and replaced with standard media and CHX (Sigma; final concentration of $100 \mu \mathrm{g} / \mathrm{ml}$ ) or vehicle (DMSO, Sigma). At subsequent time points, cells were washed twice in ice-cold PBS supplemented with CHX $(50 \mu \mathrm{g} / \mathrm{ml})$ and lysed in RIPA buffer (1\% NP-40, 0.1\% SDS, 50 mu Tris- $\mathrm{HCl} \mathrm{pH}$ 7.4, $150 \mathrm{~mm} \mathrm{NaCl}, 0.5 \%$ sodium deoxycholate, $1 \mathrm{~mm}$ EDTA). All buffers used in this study were supplemented with complete protease inhibitor mixture (Roche). Samples were then processed for Western blot. In indicated experiments, vehicle (DMSO), MG-132 (5 $\mu \mathrm{M})$, epoxomicin (100 nM), or 3-methyladenine (3-MA) (10 mM) (all from Sigma) was added $30 \mathrm{~min}$ following the addition of CHX.

RNA isolation and mRNA measurements. RNA was extracted from untransfected and transfected HEK293 cells using the RNeasy Mini Kit (QIAGEN). Total RNA from C. elegans was purified using TRIzol reagent (Invitrogen) followed by DNase I (Promega) digestion. A total of $1 \mu \mathrm{g}$ of DNase-treated RNA was reverse transcribed using the iScript cDNA syn- thesis kit (Bio-Rad) according to the manufacturer's protocol. The cDNAs were subjected to real-time qPCR in a total volume of $25 \mu \mathrm{l}$, containing $1 \times$ Power SYBR Green Master Mix (Invitrogen) and $200 \mathrm{~nm}$ primer. The qPCRs were amplified and analyzed in triplicate using StepOne RealTime PCR system (Invitrogen). To enable normalization of the input target cDNA added to each well, the endogenous controls, $\alpha$ tubulin $(t b a-1)$ for $C$. elegans experiments, and $\beta$ actin for HEK293 cell experiments were amplified simultaneously in a separate reaction well but under identical thermal cycling conditions. Amplification data were analyzed, and relative quantification data were obtained using the StepOne software version 2.2.2. Relative expression levels were quantified using the $\delta$ - $\delta$ CT method. Experiments were repeated three independent times. Primers for amplification of target mRNA were as follows: hTDP-43, 5' -ATGGAAAACAACCGAACAGG-3' and 5' -AAAGCCAAA CCCCTTTGAAT- $3^{\prime} ; \beta$-actin, $5^{\prime}$-CTCTTCCAGCCTTCCTTCCT-3' and $5^{\prime}$-AGCACTGTGTTGGCGTACAG-3'; tba-1, 5'-AAGATGCCG CCAACAACTAC- ${ }^{\prime}$ and $5^{\prime}$-CCTCCTCCGAATGAATGAAA-' 3 .

Soluble versus insoluble preparations. For all soluble/insoluble preparations, cells were lysed in RIPA buffer and sonicated (20\% strength, $10 \mathrm{~s}$ ). Lysates were then briefly centrifuged to remove cellular debris $(5000 \times \mathrm{g}$, $\left.10 \mathrm{~min}, 4^{\circ} \mathrm{C}\right)$. Supernatant was then centrifuged $(100,000 \times \mathrm{g}, 30 \mathrm{~min}$, $4^{\circ} \mathrm{C}$ ), and the supernatant was considered the "soluble" fraction. The pellet was washed in RIPA buffer and recentrifuged $(100,000 \times g, 30 \mathrm{~min}$, $\left.4^{\circ} \mathrm{C}\right)$. Supernatant was discarded. The pellet was resuspended in urea buffer ( 8 m urea, $4 \%$ CHAPS, 50 mm DTT, 40 mм Tris, pH 8.0, 2.5 mм EDTA) and considered the "insoluble" fraction. Samples were then processed for Western blot.

Sequential soluble and insoluble preparation from C. elegans. Sequential soluble and insoluble preparations were performed as previously described (Liachko et al., 2010). The total protein fraction was collected by homogenizing worms in RAB high salt buffer (100 mM MES (2- $(N$ morpholino)ethanesulfonic acid), $1 \mathrm{~mm}$ EGTA, $0.5 \mathrm{~mm} \mathrm{MgSO}_{4}, 0.75 \mathrm{M}$ $\mathrm{NaCl}, 20 \mathrm{~mm} \mathrm{NaF}$ ). The packed worm pellet was resuspended twice in low-salt buffer (10 mu Tris, 5 mm EDTA, 10\% sucrose, $\mathrm{pH} 7.5$ ) and lysed by sonication. The homogenate was centrifuged at $25,000 \times g$ for $30 \mathrm{~min}$, and the supernatant was considered the soluble low-salt buffer fraction. The low-salt buffer pellet was extracted with nonionic detergentcontaining buffer (TX) (10 m M Tris, 5 mm EDTA, 1\% Triton X-100, 10\% sucrose, $\mathrm{pH} 7.5$ ) and centrifuged for $20 \mathrm{~min}$ at $180,000 \times g$. The supernatant was considered the soluble TX fraction. The pellet was extracted with ionic detergent-containing buffer (SARK) (10 mM Tris, $5 \mathrm{~mm}$ EDTA, $1 \%$ Sarkosyl, 10\% sucrose, pH 7.5) and centrifuged at 180,000 $\times$ $g$ for $20 \mathrm{~min}$. The supernatant was considered the soluble SARK fraction. The final detergent-resistant pellet was resuspended in UREA $(30 \mathrm{~mm}$ Tris, $7 \mathrm{~m}$ urea, $2 \mathrm{~m}$ thiourea, $4 \%$ CHAPS, $\mathrm{pH}$ 7.5). This was considered the insoluble fraction. All buffers contained complete protease inhibitor mixture (Roche) and 0.5 mM PMSF.

RAD-23 expression manipulation and TDP-43 abundance. HEK293 cells were cotransfected as outlined above in a 3:1 ratio of miRNA to TDP-43 expression construct. After $48 \mathrm{~h}$, cells were lysed in RIPA buffer and samples were processed for Western blot. For RNAi rescue experiment, $2 \mu \mathrm{g}$ of LacZ or appropriate hR23A or hR23B RNAi-resistant cDNA was cotransfected. To generate RNAi-resistant cDNA, three silent mutations were introduced into the miRNA target sequence using the QuikChange Lightning Multi-Site Mutagenesis kit (Agilent) per the manufacturer's protocol. Mutations introduced into hR23A or hR23B target sequence are outlined here (nucleotide mutations introduced are italicized): for hR23A, 5'-CCAAAATATGCGCCAGGTGAT-3'; for hR23B, 5' -TGGTGACCGAAATCATGTCAA-3'. Mutated cDNAs were sequenced for correctness before use.

Mouse strains. Male heterozygote G93A mutSOD1 mice on the congenic C57BL/6 background (strain 004435; The Jackson Laboratory) were backcrossed with C57BL/6 mice. Nontransgenic littermates served as control mice. Only male G93A mutSOD1 mice and control littermates were used for experimentation. Mice were fed a standard diet (Purina 5010) and were housed on a 12/12 h light/dark cycle. Genotypes were determined by PCR using tail snip DNA. Primer sequences were as follows: 5'-CGCGACTAACAATCAAAGTGA-3'; 5'-CATGAGCCCTAATCCATCTGA-3' 5' $^{\prime}$-GTAGGTGGAAATTCTAGCATCATCC-3'; and 
A
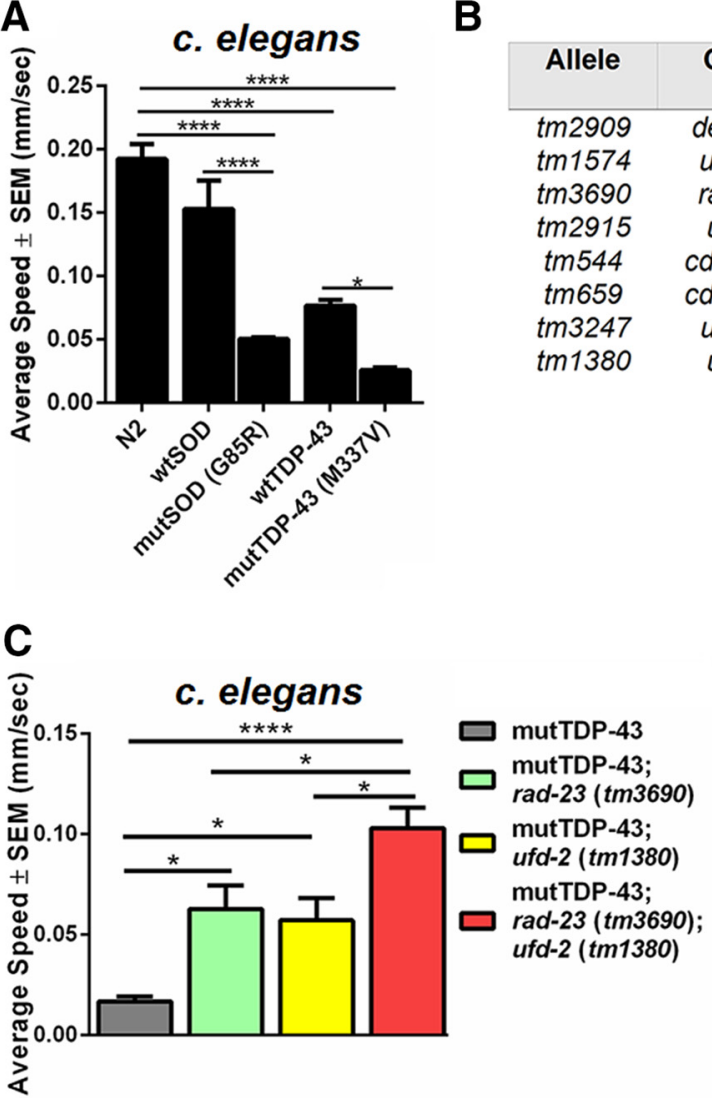

B

\begin{tabular}{|c|c|c|}
\hline \multicolumn{2}{c}{ C. elegans } \\
\hline Allele & Gene & $\begin{array}{c}\text { Effect on mutTDP43 Locomotor } \\
\text { Deficit }(\boldsymbol{\Delta} \pm \text { SD \%) }\end{array}$ \\
\hline$t m 2909$ & derlin-1 & Lethal \\
$t m 1574$ & $u b q l-1$ & No Effect $(113.7 \pm 1.1 \%)$ \\
$t m 3690$ & rad-23 & Suppressor $(191.0 \pm 4.5 \%)^{*}$ \\
$t m 2915$ & ufd-3 & Suppressor $(171.7 \pm 0.3 \%)^{* * * *}$ \\
$t m 544$ & $c d c-48.1$ & No Effect $(85.5 \pm 2.0 \%)$ \\
$t m 659$ & $c d c-48.2$ & No Effect $(127.4 \pm 0.7 \%)$ \\
$t m 3247$ & $u b x n 4$ & Enhancer $(54.7 \pm 1.9 \%)^{* * *}$ \\
$t m 1380$ & ufd-2 & Suppressor $(221.2 \pm 7.3 \%)^{*}$ \\
\hline
\end{tabular}

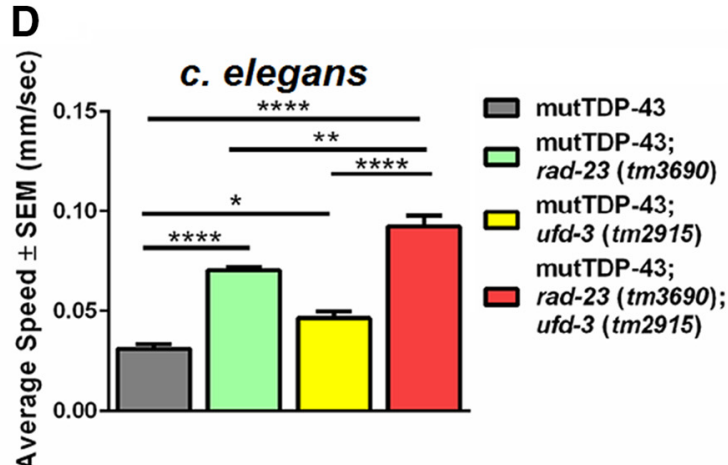

Figure 1. Locomotor defects of C. elegans models of ALS and their modification by the loss of ERAD and UPS genes. $A$, Pronounced defects in locomotion were seen in the animals overexpressing mutSOD1, wtTDP-43, and mutTDP-43 in the nervous system in comparison with N2 (WT) $\left(F_{(4,20)}=36.75, p<0.0001\right.$ ). ${ }^{*} p<0.05$ (Dunnett's multiple-comparison test). ${ }^{* * * *} p<0.001$ (Dunnett's multiple-comparison test). $\boldsymbol{B}$, Locomotion of mutTDP-43 animals in the background of various mutant ERAD and UPS alleles. Average speed of animals of indicated genotypes in a $30 \mathrm{~s}$ forced swimming assay in M9. Both suppressors and enhancers were found. No change, There was no significant change in the locomotor deficit of that background ( $p>0.05$, Student's $t$ test). Enhancer, There was a significant decrease in the average speed of the animals ( $p<0.05$, Student's $t$ test). Suppressor, There was a significant increase in the average locomotor speed of those animals $(p<$ 0.05, Student's $t$ test). $c d c-48.1$ (tm544); $c d c-48.2$ (tm659) mutants are synthetic lethal; therefore, the effect of both mutants together cannot be tested in this study. C, Loss of rad-23 and ufd-2 suppresses mutTDP-43 toxicity likely via independent pathways. Average speed of animals of indicated genotypes in a 30 s forced swimming assay in M9. A one-way ANOVA reveals group differences in the average speed of mutTDP-43, mutTDP-43; rad-23 (tm3690), mutTDP-43; ufd-2 (tm1380), and mutTDP-43; rad-23 $(\operatorname{tm} 3690)$; ufd-2 $(\operatorname{tm} 1380)\left(F_{(3,16)}=13.41 ; p=0.0001\right)$. ${ }^{*} p<0.05$. ${ }^{* * * *} p<0.001$. D, Loss of rad-23 and ufd-3 suppresses mutTDP-43 toxicity via likely independent pathways. Average speed of animals of indicated genotypes in a $30 \mathrm{~s}$ forced swimming assay in M9. A one-way ANOVA reveals group differences in the average speed of mutTDP-43, mutTDP-43; rad-23 (tm3690), mutTDP-43; ufd-3 (tm2915), and mutTDP-43; rad-23 (tm3690); ufd-3 (tm2915) $\left(F_{(3,16)}=60.55 ; p<0.0001\right) .{ }^{*} p<0.05 .{ }^{* *} p<0.01$. ${ }^{* * *} p<0.001$.

5'-CTAGGCCACAGAATTGAAAGATCT-3'. All animals were treated in strict accordance with the National Institutes of Health Guide for the Care and Use of Laboratory Animals, and all animal care and experimental protocols were approved by the Children's Hospital of Philadelphia Institutional Animal Care and Use Committee.

Ubiquitination assays. Vehicle (DMSO) or MG-132 (5 $\mu \mathrm{M})$ was added $12 \mathrm{~h}$ before cell lysis. Cells were lysed in RIPA buffer supplemented with $50 \mathrm{~mm} N$-ethylmaleimide to inhibit deubiquitinase activity, and mycTDP-43 was immunoprecipitated where relevant using the Immunoprecipitation Kit (Thermo Scientific) per the manufacturer's protocol. Samples were then processed for Western blot.

Immunohistochemistry. Patient tissue was deparaffinized. Endogenous peroxidase was blocked with 3\% hydrogen peroxide in methanol for 30 min. Sections were washed in water and immersed in $0.1 \mathrm{M}$ Tris buffer, $\mathrm{pH} 7.6$, and $0.1 \mathrm{~m}$ Tris/2\% FBS for 5 min each. Sections were incubated with $\alpha$-hR23A and $\alpha$-hR23B mouse antibody (Abcam) or preimmune mouse IgG control. After washing with $0.1 \mathrm{~m}$ Tris buffer, $\mathrm{pH}$ 7.6, and $0.1 \mathrm{M}$ Tris/2\% FBS, sections were incubated with biotinylated goat antimouse IgG (1:200; Vector Laboratories) for $30 \mathrm{~min}$ at room temperature. After washing with $0.1 \mathrm{~m}$ Tris buffer, $\mathrm{pH} 7.6$, and $0.1 \mathrm{~m}$ Tris/2\% FBS, sections were then incubated with Vectastain $\mathrm{ABC}$ (Vector Laboratories) for $45 \mathrm{~min}$. After washing with $0.1 \%$ PBST followed by $0.1 \mathrm{M}$ Tris, $\mathrm{pH} 7.5$, and $0.3 \mathrm{M} \mathrm{NaCl}$, peroxidase activity was detected with DAB (Dako). Slides were then dehydrated in an ascending series of ethanol and coverslipped.
Statistics. Statistical analysis was performed using GraphPad Prism version 6.00 for Windows (GraphPad Software; www.graphpad.com). Student's unpaired $t$ test was used for all two-group comparisons. For data containing more than three groups, a one-way ANOVA with Dunnett's multiple-comparisons test was used. For survival analysis, a logrank (Mantel-Cox) test was used. The threshold for significance was always set to $p<0.05$.

\section{Results}

Loss of ERAD components modifies ALS phenotypes in C. elegans

We asked whether mutant loss-of-function versions of ERAD or unfolded protein response genes (Table 1) suppressed or enhanced the proteotoxic insults relevant to neurodegenerative disease. We used C. elegans, engineered to express WT or mutSOD1 (J. Wang et al., 2009) and WT or mutTDP-43 (Liachko et al., 2010) in the nervous system. As previously reported, these ALS models of mutSOD1 and mutTDP-43 display a severe locomotor deficit and swim at $\sim 10 \%$ the speed of WT (N2 Bristol) animals (Fig. 1A) (Lim et al., 2012). To identify modifiers of mutTDP-43, ERAD mutants were placed on the mutTDP-43 background, and the effect on locomotion was determined. None of the ERAD 
mutants on their own showed any change compared with WT animals in a swimming assay at the young adult stage (L4 stage + $1 \mathrm{~d})$ tested (data not shown).

Of the modifiers found using this approach (Fig. 1B), we chose to focus on RAD-23 for multiple reasons. First, based on RAD-23's role as a shuttle between ubiquitinated substrates and the proteasome (Schauber et al., 1998), we anticipated that loss of rad-23 would worsen the mutTDP-43 phenotype, and this is the opposite of what we found. Second, RAD-23 has an additional role in NER, and NER defects have been linked to neurodegeneration (Jaarsma et al., 2011; Madabhushi et al., 2014). Third, rad-23 mutants showed the strongest suppression among the modifiers. Finally, the other identified suppressors of mutTDP-43 appeared to do so through independent pathways (Fig. 1C,D). The other identified suppressors, loss of $u f d-2$ (Fig. 1C) and loss of ufd-3 (Fig. 1D), both resulted in an additive suppression of the locomotor deficit when placed on the mutTDP-43 background with loss of rad-23.

\section{Loss of rad-23 suppresses two models of ALS}

In addition to the first rad-23 mutant used (tm3690), we found that a second mutant of rad-23 (tm2595) (Fig. 2A) also showed a twofold suppression of the locomotion deficit caused by mutTDP-43 (Fig. $2 B, C$ ) and mutSOD1 (Fig. $2 D, E)(p<0.05)$. The mutations used are deletions in different portions of RAD23. In addition, neither rad-23 mutant affected the locomotion of transgenic worms expressing wtSOD1 or wtTDP-43. Rad-23 mutants alone were identical to WT in the swimming assay (Fig. $2 F$ ).

To understand whether it was loss of rad-23 in the nervous system or other tissue suppressing the locomotor deficit, we used RNAi and rescue approaches. We found that mutSOD1 fed rad-23 RNAi showed no suppression of the locomotor deficit (Fig. 2G). In contrast, mutSOD1 animals fed rad-23 RNAi, where the RNAi effect is reduced in peripheral tissues and boosted in the nervous system (mutSOD; sid-1; $\mathrm{P}_{\text {unc-119 }}:: \mathrm{SID}-1$ ), showed an approximately twofold suppression of the mutSOD1 locomotor deficit $(p<0.01$; Fig. $2 G)$ (Calixto et al., 2010; Lim et al., 2012). These data suggest that loss of $\mathrm{rad}-23$ in the nervous system protects against mutSOD1.

Outcrossing the rad-23 (tm3690) allele rescued mutTDP-43 toxicity, suggesting that the suppression in the rad-23 background is not due to loss of expression of the mutTDP-43 transgene (Fig. 2H). We also generated several lines overexpressing the genomic C. elegans RAD-23 locus under the control of a nervous system-specific promoter $\left(\mathrm{P}_{\text {unc-119 }}\right)$. We found that overexpression of RAD-23 in the nervous system suppressed the beneficial effect of loss of rad-23 in mutTDP-43; rad-23 animals (Fig. 2I), but overexpression of RAD-23 in the nervous system of mutTDP-43 alone (mutTDP-43; $\mathrm{P}_{\text {unc-119: }}:$ RAD-23) had no effect on the average speed of mutTDP-43 (Fig. 2J). In sum, these data indicate that loss of rad-23 acts in a cell-autonomous manner within the nervous system to suppress mutTDP-43 and mutSOD1 toxicity.

Expression of mutTDP-43 in the C. elegans nervous system leads to neurodegeneration of the GABAergic motor neurons causing motor neuron death, broadening of the axons, and gaps in the ventral nerve cord (Liachko et al., 2010). We examined GABAergic motor neurons in WT, mutTDP-43, and mutTDP-43; rad-23 animals and found that loss of rad-23 reduced the number of animals that displayed broadening of axons in the mutTDP-43 background (Fig. $3 A$ ) and also reduced the number of gaps in the ventral nerve cord in the mutTDP-43 background (Fig. 3B). Overall, we found that loss of rad-23 suppressed the degeneration of GABAergic neurons caused by mutTDP-43 (Fig. 3C). Thus, loss of rad-23 suppresses both the locomotor deficit and neurodegenerative phenotype associated with mutTDP-43.

To date, the tissue expression pattern of C. elegans RAD-23 has not been defined. To address this, we created a worm expressing an RAD-23::GFP translational fusion protein expressed under the control of the endogenous RAD-23 genomic locus. We detected RAD-23 expression throughout the animal at the young adult (L4 $+1 \mathrm{~d}$ ) stage (Fig. 4A-C), including neuronal cell bodies and processes (Fig. $4 D$ ), the vulva (Fig. $4 E$ ), the nerve cord (Fig. $4 F$ ), and throughout the head (Fig. $4 G$ ).

\section{Loss of rad-23 protects against proteotoxicity at the cost of DNA damage}

Because loss of rad-23 protected against two ALS-associated proteins, we wondered whether loss of rad-23 had broader beneficial actions. Because neurodegeneration is often age-related, we looked at age-dependent decline in motor function in C. elegans using multidimensional biomechanical profiling software (Krajacic et al., 2012). The average speeds of WT and rad-23 mutants were identical at the L4 and young adult stage. However, rad-23 mutants showed increased average speeds compared with WT in later ages at $4 \mathrm{~d}(p<0.05)$ and $5 \mathrm{~d}(p<0.05)$ after L4 (Fig. $5 A)$. Loss of rad-23 also resulted in increased force (Fig. $5 B$ ), and power (Fig. $5 C$ ) compared with WT at these ages $(p<0.05)$. Moreover, rad-23 had a more coordinated biomechanical profile than WT at $5 \mathrm{~d}$ after L4 (Fig. 5D).

ALS and other forms of neurodegeneration show increased levels of ER stress, and attenuation of ER stress has been shown to be beneficial (Vaccaro et al., 2013; Walker et al., 2013; Thompson et al., 2014). We investigated whether loss of rad-23 attenuated $C$. elegans' response to ER stress, induced by tunicamycin. The lifespans of WT and rad-23 mutants exposed to vehicle are identical; in contrast, rad-23 mutants show an extension of their lifespan by $22.2 \%$ compared with WT when both strains are grown on tunicamcyin $(p<0.0001)$ (Fig. 5E). In a second stress assay, we found that loss of rad-23 conferred an $\sim 25 \%$ extension of lifespan at high heat $\left(34^{\circ} \mathrm{C} ; p<0.0001\right)$ (Fig. $\left.5 F\right)$.

Because rad-23 was originally identified in yeast by having increased sensitivity to UV irradiation (Prakash et al., 1993), we examined UV sensitivity in loss of rad-23 backgrounds (Lans et al., 2010). There was no difference in UV sensitivity between WT and animals overexpressing SOD1 or TDP-43. In contrast, both rad-23 mutants ( $t m 2595$ and $t$ m3690) showed a hypersensitivity to UV stress compared with WT $(p<0.0001)$. This result confirms that the rad-23 mutants used in this study are very likely null for rad-23. Interestingly, overexpressing either mutSOD1 or mutTDP-43 in the loss of rad-23 backgrounds causes a synthetic hypersensitivity on a UV sensitivity assay compared with loss of rad-23 alone $(p<0.0001)$ (Fig. $5 G$ ). These data suggest that loss of rad-23 confers a specific resistance to proteotoxic insults and age-related functional decline, but a deficit in DNA damage repair.

\section{Loss of rad-23 does not protect against mutTDP-43 toxicity via several known genetic pathways}

We examined mutants in molecular components known to associate with RAD-23 in ERAD. PNG-1 physically and genetically interacts with RAD-23 in yeast and C. elegans (Habibi-Babadi et al., 2010). We found no suppression of mutTDP-43 toxicity by png-1 (cy9) (Fig. 6A). UFD-3 mutants in yeast have reduced bulk ubiquitin levels (Johnson et al., 1995) and can antagonize UFD-2 (Rumpf and Jentsch, 2006), an interactor of RAD-23 (Kim et al., 

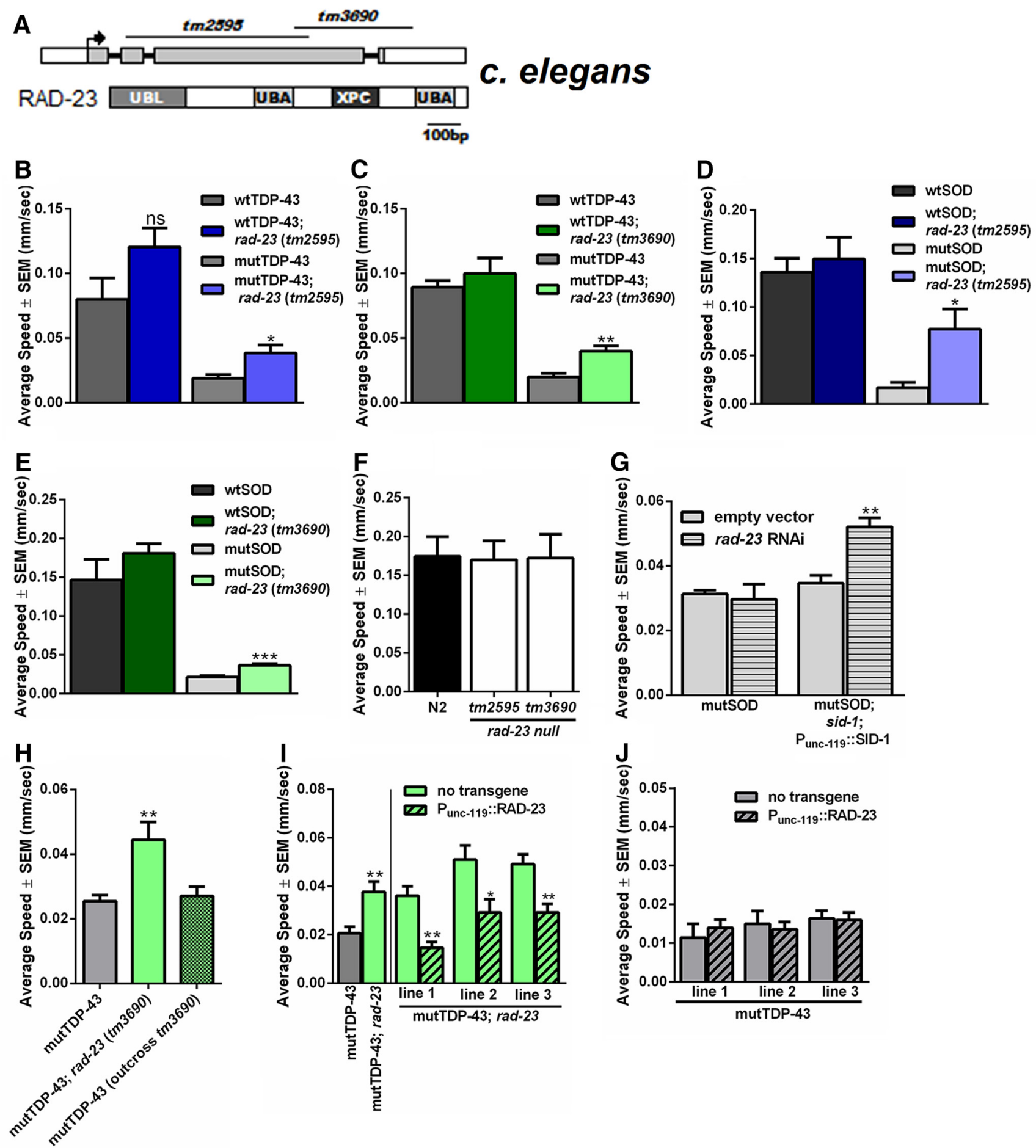

Figure 2. Loss of rad-23 in C. elegans protects against models of ALS via an effect in the nervous system. $A$, Schematic of C. elegans RAD-23 gene with predicted protein shown. Lines indicate areas with insertions and/or deletions in the used mutants. $\boldsymbol{B}, \boldsymbol{C}$, Loss of rad-23 $(\mathrm{tm} 2595)(\boldsymbol{B})$ or $(\mathrm{tm} 3690)(\boldsymbol{C})$ causes a twofold suppression in the locomotor deficit of mutTDP-43 but has no effect on wtTDP-43 ( $p=0.108$ for tm2595 and $p=0.473$ for tm3690). $\boldsymbol{D}, \boldsymbol{E}$, Loss of rad-23 (tm2595) (D) or (tm3690) (E) leads to a twofold suppression in the locomotor deficit of mutSOD1 animals but has no effect on the wtSOD1 animals $\left(p=0.615\right.$ for tm2595 and $p=0.274$ for tm3690). $\boldsymbol{F}$, Neither rad-23 allele is different from WT speed in the swimming assay. $F_{(2,12)}=0.006579 ; p=0.9934$. G,

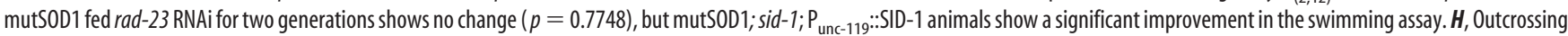
the rad-23 (tm3690) allele from mutTDP-43; $t m 3690$ leads to a rescue of the mutTDP-43 locomotor deficit. $I$, 0verexpression of RAD-23 in the nervous system of mutTDP-43; rad-23 (tm3690) is sufficient to rescue the mutTDP-43 locomotor deficit.J, There is no change in the average locomotor speed of the mutTDP43 animals when RAD-23 is overexpressed in the nervous system using the $P_{\text {unc-119 }}$ promoter $\left(F_{(5,24)}=1.112 ; p=0.3801\right) .{ }^{*} p<0.05$ (Student's $t$ test). ${ }^{* *} p<0.01$ (Student's $t$ test). ${ }^{* *} p<0.005$ (Student's $t$ test). ns, Not significant.

2004), and CDC-48 (Böhm et al., 2011). We found that $u f d-2$ (tm1380) and $u f d-3$ (tm2915), but not $c d c-48.1$ (tm544) or $c d c-48.2$ (tm659), also suppressed the locomotor deficit of mutTDP-43 (Fig. 1B). We could not study the effect of loss of $c d c-48.1$ and $c d c-48.2$ together because loss of both genes results in a larval lethality. Given our finding reported here and the existing evidence that the UFD proteins can associate with RAD-23, we tested whether there was a genetic interaction 
A

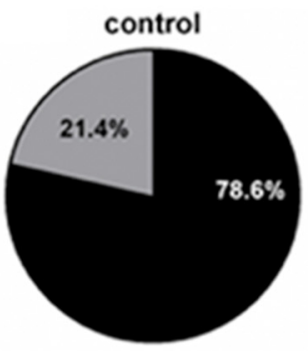

c. elegans

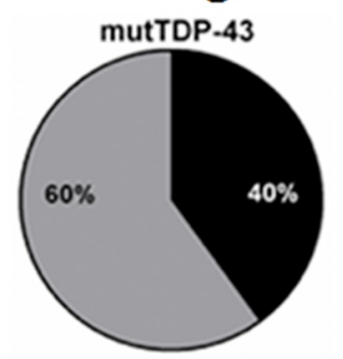

$\%$ normal

$\%$ with broadening of axons

B

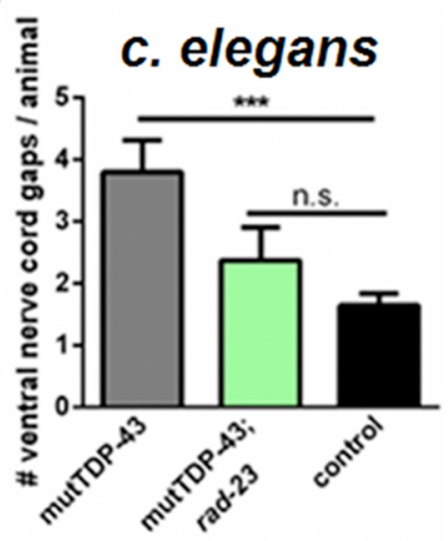

C
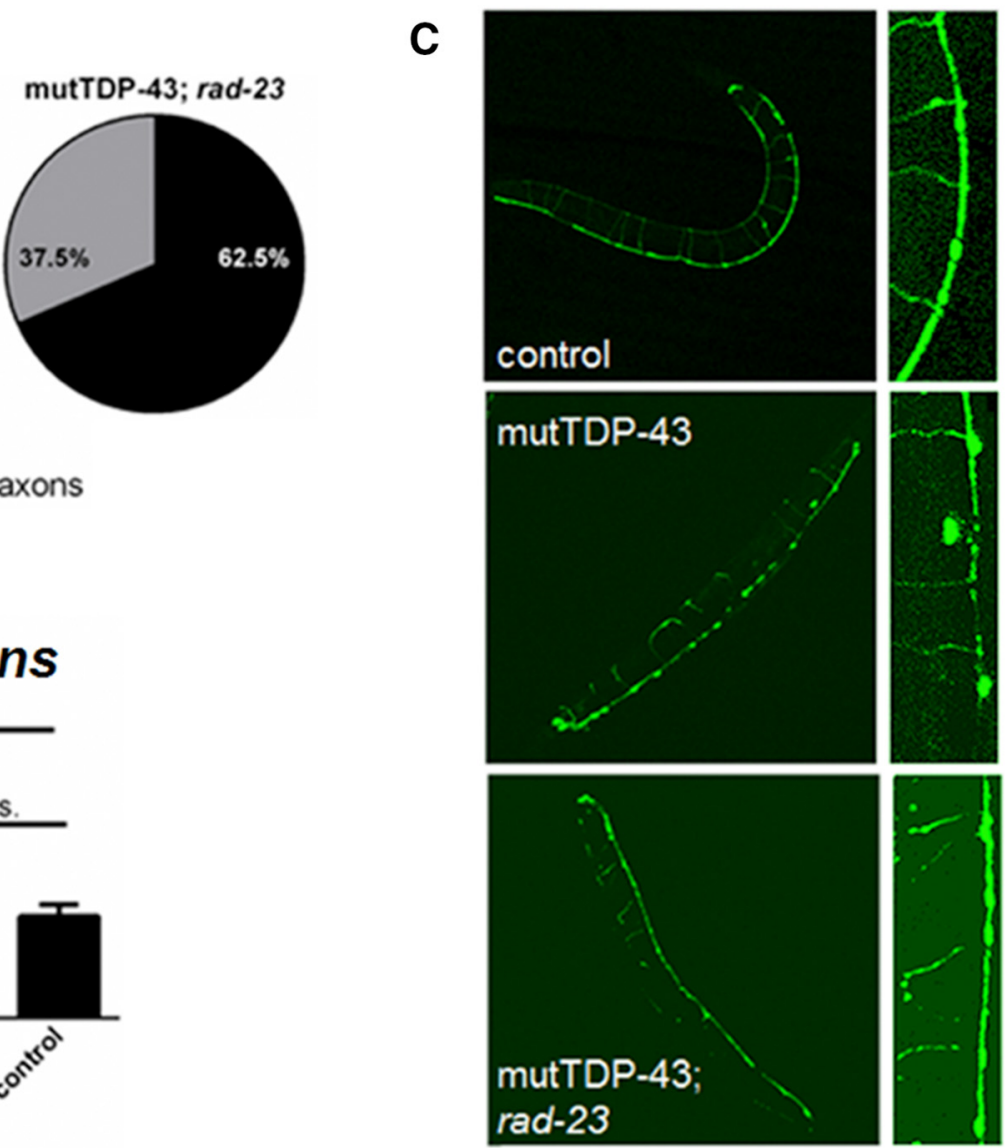

$P_{\text {unc. } 25}:: G F P$

GABAergic motor neurons

c. elegans

Figure 3. Loss of rad-23 in C. elegans protects against neurodegeneration following expression of mutTDP-43 in vivo. We generated animals with GABAergic motor neurons labeled with GFP using

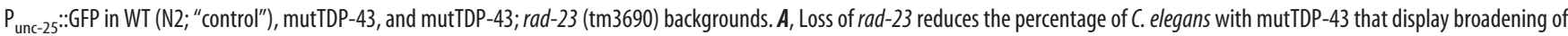
axons. $\boldsymbol{B}$, mutTDP-43 causes an increase in the number of gaps within the ventral nerve cord of animals compared with control. ${ }^{* * *} p<0.005$ (Dunnett's multiple-comparison test following one-way ANOVA). ns, Not significant. Loss of rad-23 reduces the number of ventral nerve cord gaps in the mutTDP-43 animals to WT. There is no significant difference in the number of gaps in mutTDP-43; rad-23 animals compared with control (WT). C, Representative images of WT, mutTDP-43, and mutTDP-43; rad-23 (tm3690) animals labeled with $\mathrm{P}_{\text {unc-25: }: G F P .}$
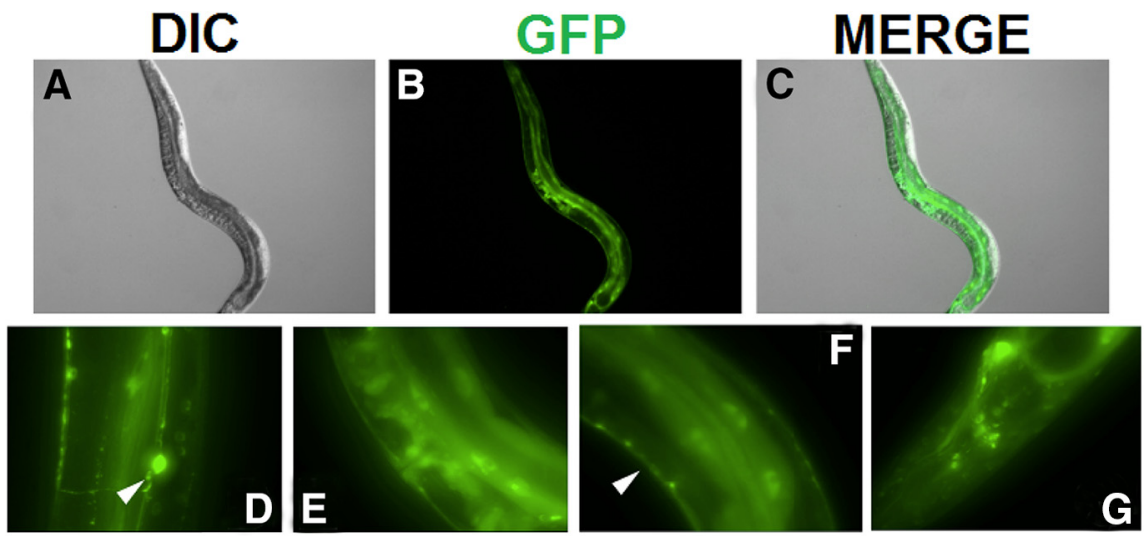

\section{c. elegans}

Figure 4. RAD-23 protein is expressed throughout the worm, including the worm nervous system. $A-C, A$ RAD-23 protein translational fusion with GFP driven by the endogenous rad-23 promoter ( $\left.\mathrm{P}_{\mathrm{RAD}-23}: \mathrm{RAD}-23:: \mathrm{GFP}\right)$ is expressed throughout the worm in young adult animals. D, RAD-23 protein is expressed in the cell body and processes of a mechanosensory neuron (arrowhead), $(\boldsymbol{E})$ vulva of the worm, $(\boldsymbol{F})$ nerve cord (arrowhead), and $(\boldsymbol{G})$ the head. between the effect of rad-23 on mutTDP-43 toxicity and either $u f d-2$ or $u f d-3$. When either $u f d-2$ or $u f d-3$ was placed on the mutTDP-43; rad-23 background, we found an additive suppression of the mutTDP-43 locomotor deficit. This observation suggests that the beneficial effect of loss of rad-23 is not through a linear pathway with $u f d-2$ or $u f d-3$ (Fig. 1C,D).

Given the link to DNA damage, we used C. elegans genetics to determine whether genes known to function with rad-23 in the NER pathway could modify the mutTDP-43 and mutSOD1 phenotypes. Strains harboring mutations in various NER components neither showed a baseline difference compared with WT in the swimming assay (data not shown) nor suppressed the mutTDP-43 phenotype (Fig. 

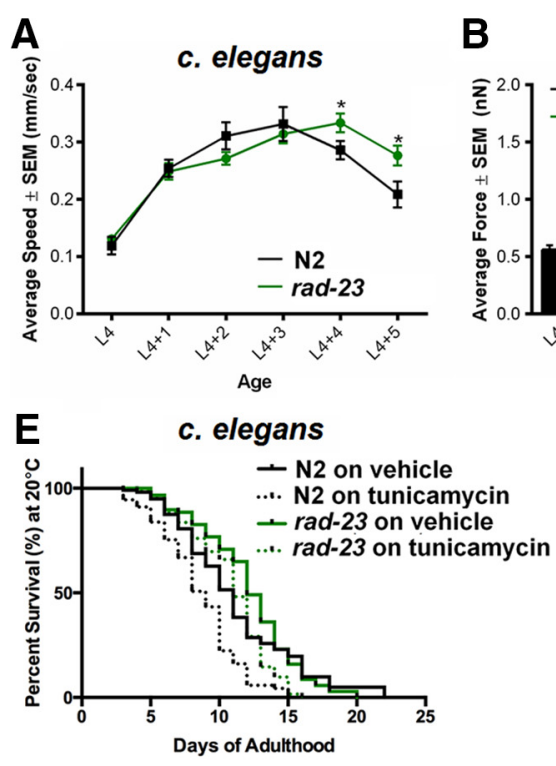
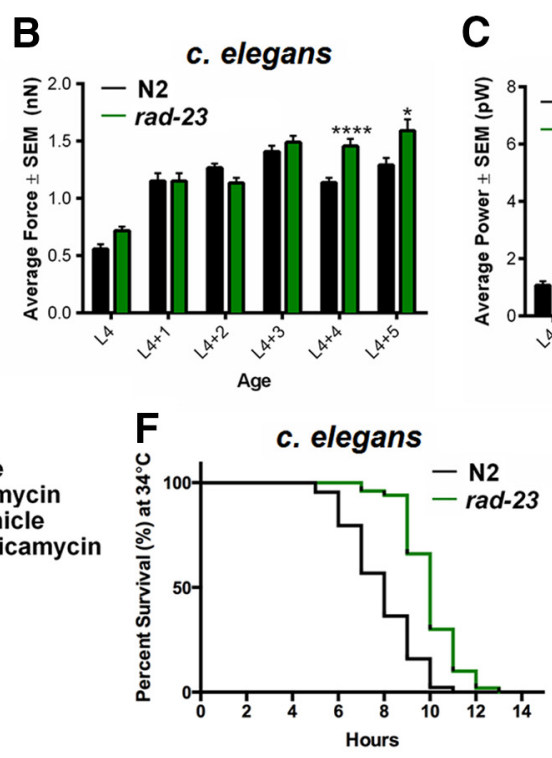

C
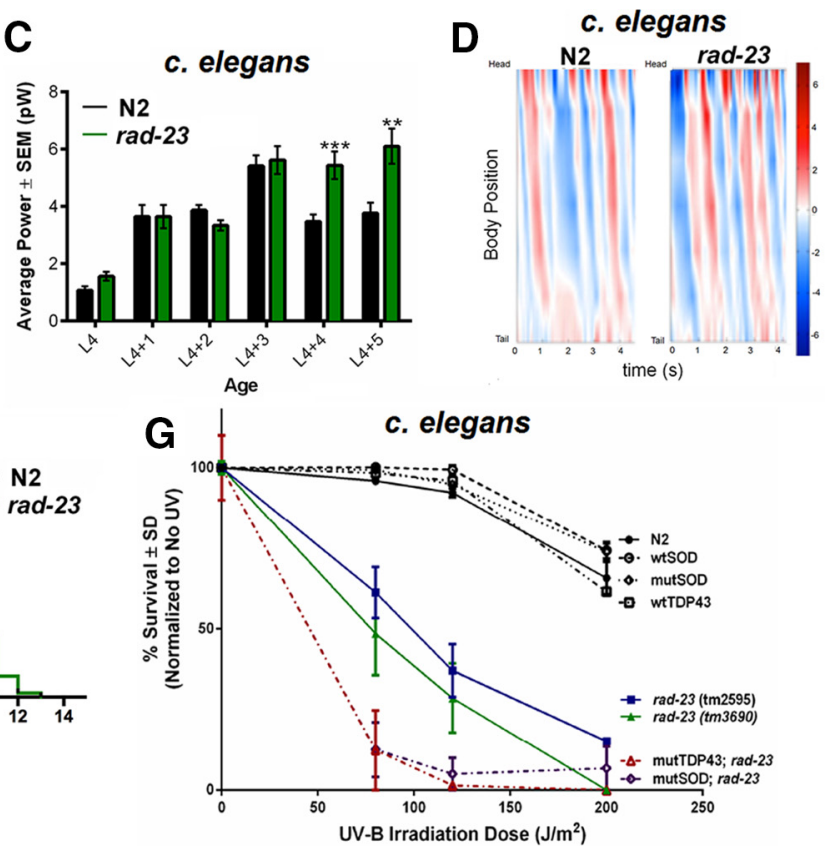

Figure 5. Loss of $R A D-23$ in C. elegans protects against aging decline and proteotoxicity. $\boldsymbol{A}-\boldsymbol{D}$, Biomechanical profiling of $N 2$ (WT) and rad- 23 ( $\operatorname{tm} 3690)$ animals $(n \geq 10 /$ group). There is no difference between WT and rad-23 (tm3690) in speed $(\boldsymbol{A})$, force $(\boldsymbol{B})$, and power $(\boldsymbol{C})$ at $\mathrm{L} 4$ through $3 \mathrm{~d}$ after $\mathrm{L} 4$. At 4 and $5 \mathrm{~d}$ after $\mathrm{L} 4$, rad-23 animals perform better in speed $(\boldsymbol{A})$, force $(\boldsymbol{B})$, and power (C) measurements than WT. D, Rad-23 animals show a more coordinated biomechanical profile at $5 \mathrm{~d}$ after $\mathrm{L} 4$ than WT. $\boldsymbol{E}$, The lifespan of rad-23 animals is extended by $22.2 \%$ compared with WT on tunicamycin $(p<0.0001)$, but the lifespans of WT and rad-23 are identical on vehicle $(p=0.646)$. $\boldsymbol{F}$, Rad-23 animals show an $\sim 25 \%$ lifespan extension during heat stress compared with WT $(p<0.0001)$. G, There are no group differences in survival among WT, wtTDP-43, mutTDP-43, wtSOD1, and mutSOD1 with increasing doses of UV irradiation $\left(F_{(4,15)}=0.1285 ; p=0.9697\right)$. There are group differences among WT, rad-23 (tm2595 and tm 3690), and mutTDP-43 and mutS0D1 in the rad-23 (tm3690) background $\left(F_{(6,21)}=2.961, p<0.05\right)$. As predicted, loss of rad-23 (tm2595 and $t m 3690)$ causes a hypersensitivity to UV stress compared with WT animals $(p<0.001)$. MutTDP-43 and mutSOD1 in the loss of rad-23 background show a synthetic hypersensitivity to UV stress $(p<0.001) .{ }^{*} p<0.05$ (Student's $t$ test). ${ }^{* *} p<0.01$ (Student's $t$ test). ${ }^{* *} p<0.005$ (Student's $t$ test). ${ }^{* * *} p<0.001$ (Student's $t$ test).

$6 B-D)$. This suggests that loss of rad-23 does not protect against mutTDP-43 via the NER pathway.

\section{Knockdown of RAD-23 in mammalian motor neurons protects against toxicity caused by TDP-43, SOD1, and ER stress}

Mammals contain two orthologs of the nematode RAD-23, and the human proteins (hR23A and hR23B) retain $40 \%$ amino acid identity with the $C$. elegans protein. We investigated whether knockdown of $h R 23 A$ or $h R 23 B$ protected against TDP-43 and SOD1 toxicity in mammalian neurons. We created miRNAs targeting endogenous $h R 23 A$ and found specific knockdown of hR23A, but not hR23B or a cotransfected GFP plasmid (Fig. $7 A, B, E$ ). A specific $h R 23 B$ miRNA was also generated (Fig. $7 C-$ $E)$. We engineered an HSV to express the designed miRNAs targeting $h R 23 A$ and $h R 23 B$. Because HSV is a neurotropic virus, it will not knock down $h R 23 A$ or $h R 23 B$ in glia. We found that $h R 23 A$ and $h R 23 B$ knockdown led to specific target knockdown in rat mixed spinal cord cultures (Fig. $7 F$ ).

When mixed spinal cord cultures were infected with recombinant HSV engineered to express wtSOD1 or wtTDP-43, there was an $\sim 25 \%$ decrease in $5 \mathrm{~d}$ motor neuron survival. In contrast, when neurons were infected with an HSV engineered to express mutSOD1 or mutTDP-43, there was an $\sim 50 \%$ decrease in $5 \mathrm{~d}$ motor neuron survival. Recombinant HSV virus expressing mutSOD1 or mutTDP-43 induced statistically significant greater motor neuron death than the WT proteins (mutSOD1 vs wtSOD1, $p=0.0255$; mutTDP-43 vs wtTDP-43, $p=0.0078$; Fig. $7 G$ and Fig. $7 H$, respectively). We found that knockdown of $h R 23 A$ protected against wt and mutSOD1 toxicity $(p<0.01$ and $p<0.001$, respectively) (Fig. 7G,I), as well as wt and mutTDP-43 toxicity
( $p<0.01$ and $p<0.01$, respectively) (Fig. $7 H$ ). We found that knockdown of $h R 23 B$ also protected against the toxicity of wtSOD1 $(p<0.005)$, mutSOD1 $(p<0.001)$, wtTDP-43 $(p<$ $0.005)$, and mutTDP-43 ( $p<0.001)$ (Fig. $7 G-I)$. Thus, reducing the amount of endogenous hR23A or hR23B in mammalian spinal cord neurons protects against SOD- and TDP-43-induced motor neuron death.

To determine whether knockdown of RAD-23 orthologs in mammalian neurons protected against ER stress, mixed spinal cord neurons were infected with HSV to express an hR23A, $h R 23 B$, or control miRNA along with either LacZ to mimic a "non-ALS" condition or mutSOD1 to mimic an "ALS" condition. At $24 \mathrm{~h}$ later, neurons were treated with vehicle or tunicamycin $(2.5 \mu \mathrm{g} / \mathrm{ml})$ to induce ER stress. Motor neuron survival was assessed $48 \mathrm{~h}$ later (Fig. $7 J$ ). Under + LacZ conditions, we found that tunicamycin reduced motor neuron survival by $\sim 40 \%$ compared with vehicle. This was suppressed entirely by $h R 23 A(p<0.01)$ and $h R 23 B(p<0.05)$ knockdown, although $h R 23 A$ and $h R 23 B$ knockdown had no effect on motor neuron survival on its own. In addition, under the mutSOD1 condition, we found that $h R 23 A(p<0.05)$ and $h R 23 B(p<0.01)$ knockdown reduced toxicity of mutSOD1. Under these conditions, tunicamycin exacerbated toxicity of mutSOD1 by $\sim 10 \%$, and this was suppressed by reducing hR23A $(p<0.001)$ and hR23B $(p<0.005)$. In sum, reducing RAD-23 abundance renders motor neurons resistant to invoked ER stress.

\section{hR23A expression is increased in the spinal cord of mutSOD1 mice}

Given that reduced RAD-23 expression protected against the toxicity of two ALS models, we examined the abundance of hR23A 

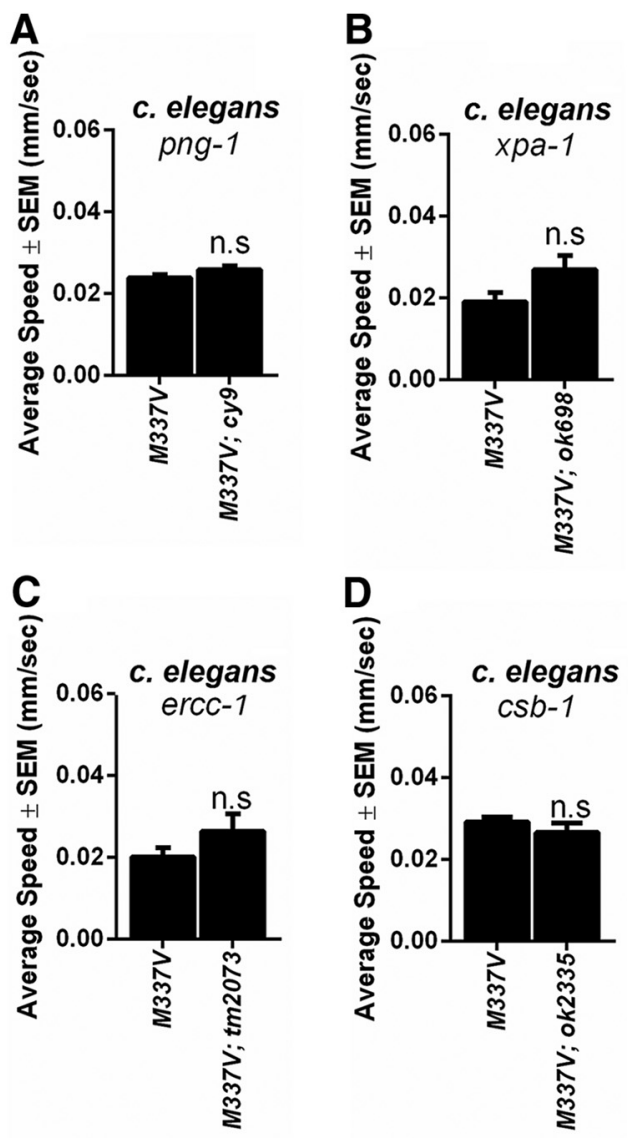

Figure 6. Loss of rad-23 does not suppress the $C$. elegans mutTDP-43 locomotor deficit via known pathways. Loss of $(\boldsymbol{A})$ png-1 (cy9), or (B) xpa-1, or $(\boldsymbol{C}) \operatorname{ercc}-1(\boldsymbol{C})$, or (D) csb-1 does not protect against the locomotor deficit caused by mutTDP-43 in the swimming assay $(p>0.05$, Student's $t$ test). One representative experiment is shown. Description of alleles: $0 k 698,913 \mathrm{bp}$ deletion; tm2073, 804 bp deletion; ok2335, 1620 bp deletion; cy9, single nucleotide polymorphism. n.S, Not significant.

and hR23B in the mouse ALS (mutSOD1 (G93A)) model compared with control. At a presymptomatic time point (P60), we found no difference in hR23A or hR23B expression in the brain and spinal cord of mutSOD1 mice compared with ageand sex-matched controls. At symptomatic and end-stage time points, we found an $\sim 50 \%$ increase in hR23A (Fig. $8 A, B$ ) expression in the spinal cord of the mutSOD1 mice at P90 $(p<0.05)$ and P120 $(p<0.01)$. There was no change in hR23B expression in the spinal cord at P90 $(p=0.8419)$ or P120 ( $p=0.3592$ ) (Fig. $8 C, D)$.

\section{Loss of RAD-23 accelerates the degradation of mutTDP-43} and mutSOD1

To begin to identify the mechanism by which loss of rad-23 confers protection against proteotoxicity, we examined the steady-state levels of wtTDP-43 and mutTDP-43 following overexpression and knockdown of RAD-23 in HEK293 cells. In accordance with data from C. elegans showing that the loss of rad-23 had no effect on the average speed of wtTDP-43 animals, neither overexpression nor knockdown of RAD-23 had an effect on wtTDP-43 abundance in HEK293 cells (Fig. 9A,B). Cotransfection of the mutTDP-43 expression construct with either the hR23A or hR23B expression construct led to a small increase in mutTDP-43 abundance (Fig. 9A,B). In contrast, when endogenous $h R 23 A$ or $h R 23 B$ was knocked down by cotransfection of the
miRNA to $h R 23 A$ or $h R 23 B$ (vs the control miRNA) along with the mutTDP-43 expression construct, we found an $\sim 90 \%$ reduction $(p<0.005)$ in the total amount of mutTDP-43 protein (Fig. $9 A, B)$. We found no change in human TDP-43 mRNA levels after RAD-23 knockdown, compared with a control miRNA (Fig. $9 C)$, suggesting that the changes in protein abundance are unlikely to be linked to an alteration in transcription.

We next examined the rate of TDP-43 and SOD1 degradation with or without knockdown of $h R 23 A$ or $h R 23 B$. TDP-43 has been reported to have a half-life of $\sim 50 \mathrm{~h}$, and ALS-linked mutations in TDP-43 result in a more stable protein than WT (Ling et al., 2010; Austin et al., 2014; Barmada et al., 2014). HEK293 cells were transfected with the plasmid expressing TDP-43 or SOD1 along with an hR23A, $h R 23 B$, or control miRNA. At $48 \mathrm{~h}$ later, new protein synthesis was inhibited by the addition of $\mathrm{CHX}$, and lysates were probed for TDP-43 or SOD1 at time intervals thereafter. Knockdown of $h R 23 A$ or $h R 23 B$ had no effect on the degradation of wtTDP-43 (Fig. $9 D, E$ ) or wtSOD1 (Fig. $9 F, G$ ). In contrast, we found that knockdown of $h R 23 A$ led to an accelerated loss of mutTDP-43 (Fig. 9D,E; $p<0.05$ ) and mutSOD1 (Fig. 9 F, $G ; p<0.01$ ) after 180 min of CHX. There was $\sim 30 \%$ less mutTDP-43 and mutSOD1 protein remaining in $h R 23 A$ knockdown compared with controls. After $270 \mathrm{~min}$ of $\mathrm{CHX}$, there was $\sim 40 \%$ less mutTDP-43 remaining in the $h R 23 A$ knockdown group compared with control $(p<0.05)$ (Fig. $9 H, I)$. To confirm that effects of RAD-23 knockdown on mutTDP-43 abundance were RAD-23 specific, we showed that we could rescue the reduced mutTDP-43 abundance in RAD-23 knockdown conditions by cotransfecting an RNAi-resistant RAD-23 cDNA $\left(\mathrm{hR} 23 \mathrm{~A}^{\text {res }}\right.$ or $\mathrm{hR} 23 \mathrm{~B}^{\text {res }}$ ) to restore RAD-23 in the HEK293 cells (Fig. 9J,K). Knockdown of $h R 23 A$ or $h R 23 B$ reduced mutTDP-43 abundance if cells were transfected with a LacZ control, but cotransfection with the RNAi-resistant RAD-23 cDNA prevented the decrease in mutTDP-43 abundance. In contrast to the observed results for mutTDP-43 and mutSOD1, we found that knockdown of $h R 23 A$ and $h R 23 B$ inhibited the degradation of $\mathrm{CPY}^{\star}$, a canonical yeast ERAD substrate, after CHX (Fig. 9L). This suggests that the inhibition of ALS-linked protein clearance by RAD-23 is specific and does not apply to all substrates.

To further confirm that it is reduced RAD-23 levels, which accelerate mutTDP-43 turnover, we used a line of RAD-23null MEFs (Okuda et al., 2004). We compared mutTDP-43 degradation during CHX treatment in $\mathrm{hR}_{2} 3 \mathrm{~A}^{-/-}$and hR23B ${ }^{-1-}$ MEFs to WT MEFs. After inhibiting protein synthesis for $180 \mathrm{~min}$, we found a $\sim 40 \%$ greater reduction in mutTDP43 abundance in hR23A- or hR23B-null MEFs versus WT MEFs (Fig. 10A). Restoring RAD-23 expression in the RAD-23-null MEFs blocked the accelerated degradation of RAD-23 (Fig. 10B).

Finally, we asked whether loss of RAD-23 affected the turnover of ALS-linked proteins in primary neurons of rat mixed spinal cord cultures. This is experimentally challenging because of the following: (1) application of CHX to these cultures for $>180 \mathrm{~min}$ is toxic; and (2) the half-life of newly synthesized SOD1 and TDP-43 in neurons is between 10-20 h (Nishitoh et al., 2008; Austin et al., 2014). Acknowledging these limitations, we infected primary spinal cord neurons with recombinant HSV expressing wtSOD1, mutSOD1, wtTDP-43, or mutTDP-43 alongside recombinant HSV expressing the RAD-23 miRNAs or a control miRNA. After $48 \mathrm{~h}$ to allow for expression and knockdown, we treated the cultures with CHX for 180 min to inhibit protein synthesis as was done previously in HEK293 cells and MEFs. We found that 

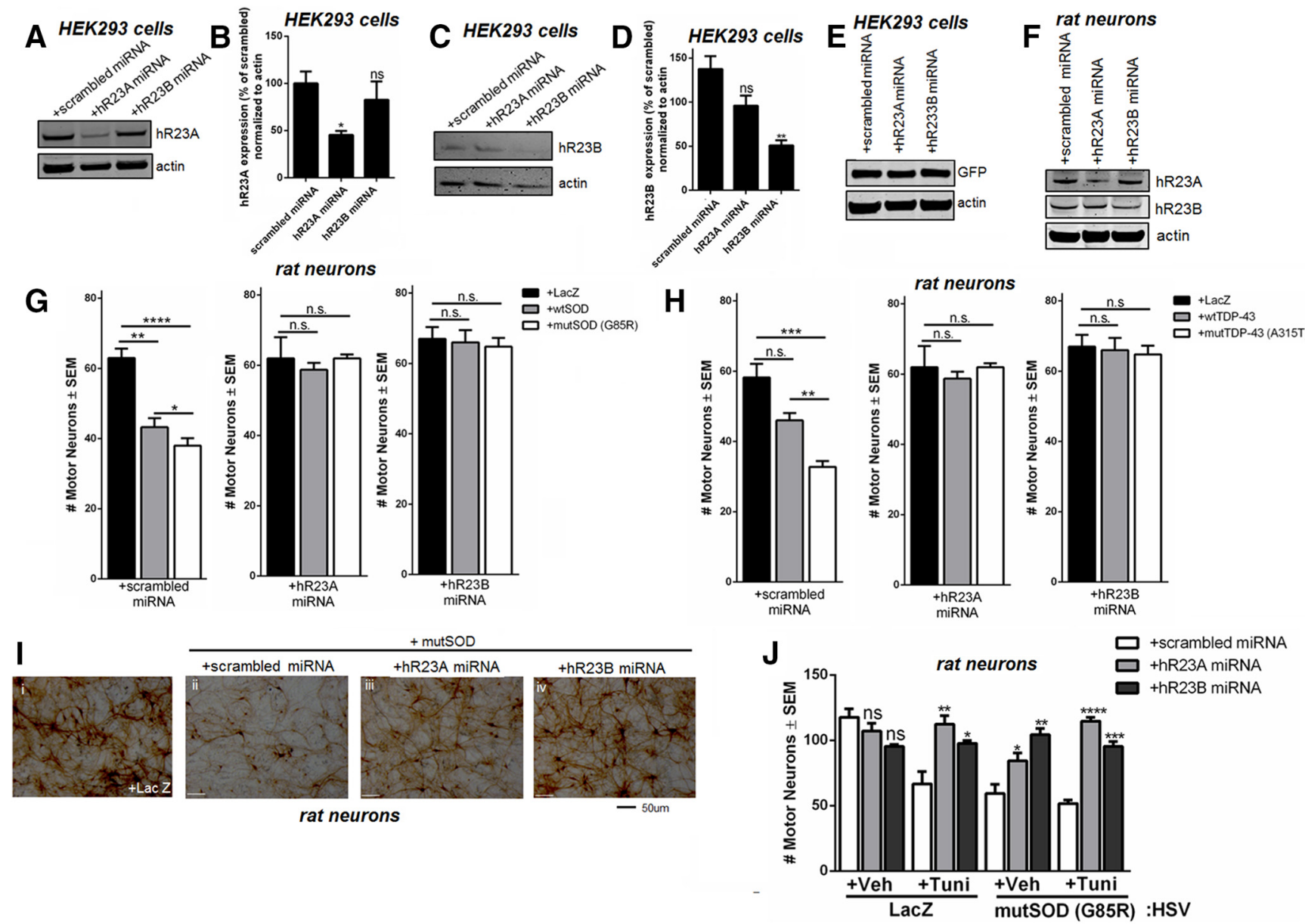

Figure 7. Knockdown of RAD-23 orthologs in mammalian motor neurons protects against toxicity of SOD1 or TDP-43. A-E, hR23A or hR23B miRNA knocks down endogenous target in HEK293 cells ( $n=3$ /group) but does not knock down the expression of a cotransfected GFP plasmid. ${ }^{*} p<0.05 .{ }^{* *} p<0.01 . F$, HSV infection of miRNA to $h R 23 A$ or $h R 23 B$ in mixed spinal cord cultures leads to specific knockdown of target protein compared with control. $G$, Infection of mixed spinal cord cultures with LacZ or an hR23A, $h R 23 B$, or control miRNA has no effect on motor neuron survival $\left(F_{(3,12)}=0.8132, p=0.3166\right)$. Knockdown of $h R 23 A$ or $h R 23 B$ protects against motor neuron death caused by wtSOD1 $\left(F_{(3,12)}=17.39, p=0.0001\right)$ and mutSOD1 $\left(F_{(3,12)}=54.64, p<0.0001\right)$. mutSOD1 infection causes a greater degree of motor neuron death than wtSOD1 $(p=0.0078)$. $\boldsymbol{H}$, Infection of mixed spinal cord cultures with LacZ or a scrambled, $h R 23 A$, or $h R 23 B$ miRNA has no effect on motor neuron survival $\left(F_{(3,12)}=0.8875, p=0.2100\right)$. Knockdown of $h R 23 A$ or $h R 23 B$ protects against motor neuron death caused by wtTDP-43 $\left(F_{(3,12)}=16.66, p=0.0001\right)$ and mutTDP-43 $\left(F_{(3,12)}=48.07 ; p<0.0001\right) .{ }^{* *} p<0.01 .{ }^{* * *} p<0.005 .{ }^{* * *} p<0.001$. ns, n.s, Not significant. MutTDP-43 infection causes a greater degree of motor neuron death than wtTDP-43 $(p=0.0255) . I$, Representative bright-field images of mixed spinal cord cultures infected as indicated stained for SMI-32 motor neuron marker. Coinfection of mutSOD1 cultures with HSV-miRNA to $h R 23 A$ or $h R 23 B$ increases motor neuron survival. $J$, Knockdown of $h R 23 A$ or $h R 23 B$ protects against motor neuron death caused by mutS0D1 $\left(F_{(2,6)}=13.99, p=0.0055\right)$ but has no effect on survival in motor neurons infected with $\operatorname{LaCZ}\left(F_{(2,6)}=4.745, p=0.0581\right)$ in cultures treated with vehicle. Knockdown of $h R 23 B$ protects cultures infected with $H S V$-LacZ $\left(F_{(2,6)}=11.82, p=0.0083\right)$ or HSV-mutSOD1 $\left(F_{(2,6)}=101.9, p<0.0001\right)$ from toxicity of ER stress induced with tunicamycin.

knockdown of hR23A or hR23B led to modestly less wtSOD1 and less mutSOD1 after 180 min of CHX in comparison with nonknockdown cultures (infected with HSV-control miRNA) (Fig. 10C). Similarly, knockdown of hR23A or hR23B led to modestly less wtTDP-43 and less mutTDP-43 after $180 \mathrm{~min}$ of CHX in comparison with nonknockdown cultures (infected with HSV-control miRNA) (Fig. 10D). The relatively smaller effect sizes may be attributable to the aforementioned technical factors. Nonetheless, in combination with the data from HEK293 cells and MEFs, our results indicate that reducing RAD-23 levels leads to accelerated degradation of toxic proteins implicated in neurodegeneration in several cell lines, including primary neurons. These data may explain why hR23A and hR23B knockdown also promoted survival after infection of both the WT and mutant ALS-linked proteins in neurons. These studies, however, also highlight the importance of cellular environment and the model organism of choice when assessing RAD-23 function.
Inhibition of the proteasome or autophagy block enhanced clearance of mutTDP-43 by RAD-23 knockdown

RAD-23 is known to interact with ubiquitinated substrates and the proteasome (Chen et al., 2002). RAD-23 overexpression can inhibit proteasomal degradation by inhibiting ubiquitination (Ortolan et al., 2000; Raasi and Pickart, 2003). To begin to explore the contribution of the proteasome or autophagy pathways in the enhanced clearance of mutTDP-43 following RAD-23 knockdown, we used several pharmacological inhibitors of the proteasome, the ubiquitin/proteasome system (UPS) more broadly, and autophagy. Briefly, HEK293 cells were transfected with the mutTDP-43 construct and the $h R 23 A, h R 23 B$, or control miRNA. Drugs targeting the UPS or autophagy pathways were added 30 min after CHX (Fig. 11A). Lysates were collected following 0 and $270 \mathrm{~min}$ of $\mathrm{CHX}$ treatment, and the amount of mutTDP-43 remaining was determined. In the vehicle (DMSO) condition, $h R 23 B$ knockdown $(p<0.01)$ reduced the amount of mutTDP-43 remaining after $270 \mathrm{~min}$ of CHX by $\sim 50 \%$ com- 
mouse samples

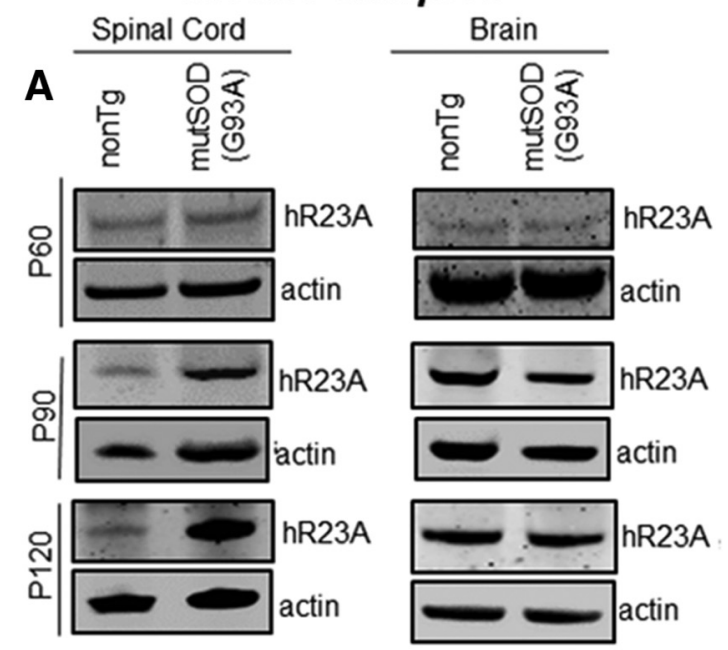

mouse samples

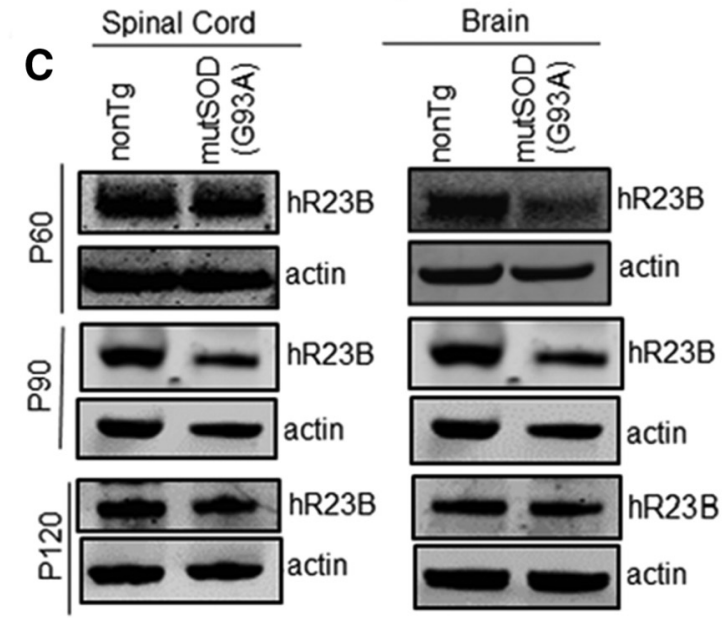

mouse samples
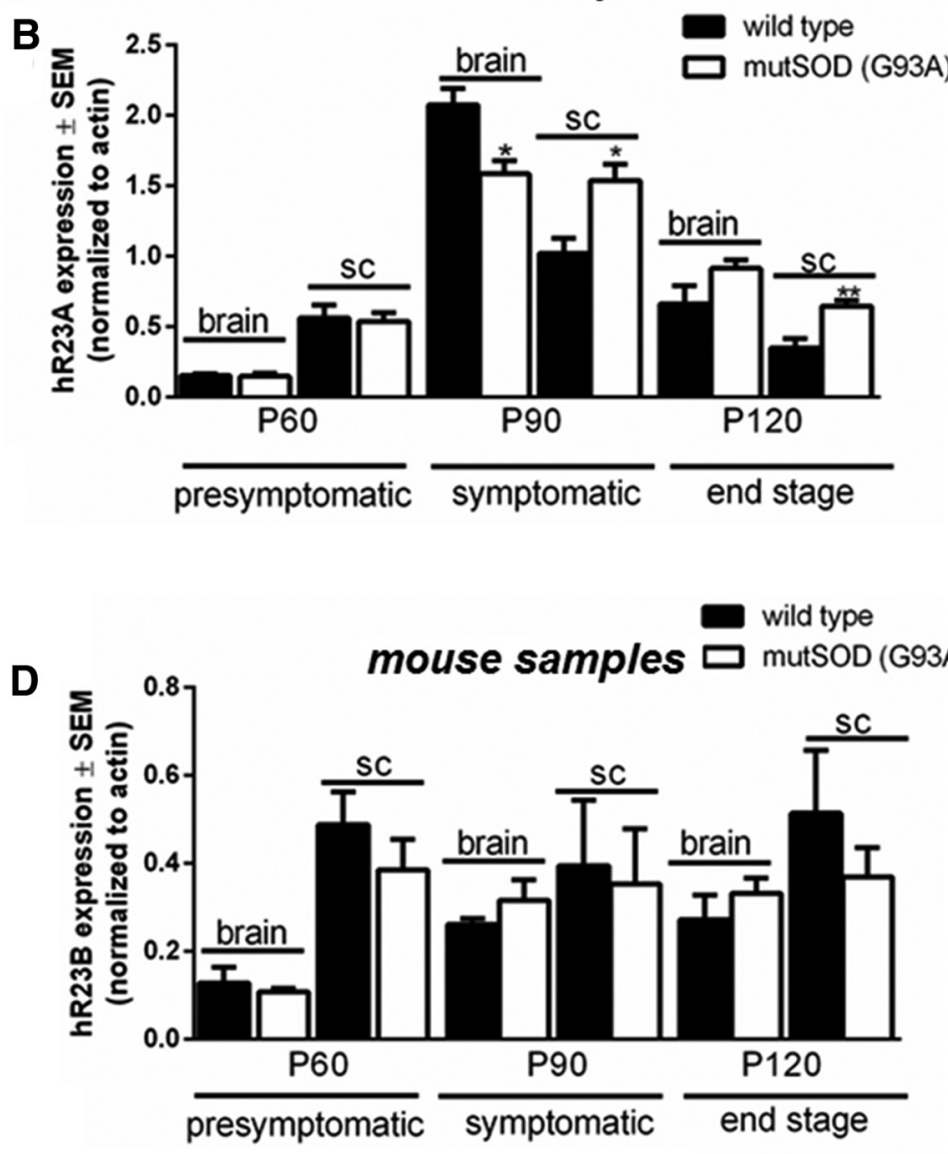

Figure 8. hR23A expression is increased in the spinal cord of mutS0D1 mice at P90 and P120. $A, B$, Representative Western blot $(\boldsymbol{A})$ and quantification $(n=3-5 / g r o u p)(\boldsymbol{B})$ of hR23A expression in the spinal cord and brain of age-matched males. hR23A expression is increased in the spinal cord of mutS0D1 mice compared with WT (C57BL6) at P90 and P120, but not at P60. $\boldsymbol{C}, \boldsymbol{D}$, Representative Western blot (C) and quantification ( $n=3-5 / g r o u p)(\boldsymbol{D})$ of hR23B expression in the spinal cord and brain of age-matched males. There is no change in $\mathrm{hR23B}$ expression in the spinal cord or brain at $\mathrm{P} 60, \mathrm{P} 90$, or P120. ${ }^{*} p<0.05$ (Student's $t$ test). ${ }^{* *} p<0.01$ (Student's $t$ test).

pared with control (Fig. $11 B, C$ ). Inhibiting the proteasome with MG-132 or epoxomicin or inhibiting the autophagic system with 3-MA was sufficient to block of the clearance of mutTDP-43 when RAD-23 was knocked down (Fig. 11C). These data suggest that the enhanced clearance of mutTDP-43 by reducing RAD-23 is mediated by the UPS and autophagy. This is in accordance with recent work in cell lines showing that mutTDP-43 is degraded by both the UPS and autophagy (Scotter et al., 2014). Future work, however, is required to determine whether loss of RAD-23 directly alters autophagy flux to impact mutTDP-43 turnover.

RAD-23 knockdown disinhibits ubiquitination of mutTDP-43

We reasoned that pharmacological inhibition of the proteasomal and autophagic pathways might both block the increased clearance of mutTDP-43 following RAD-23 knockdown because reduced RAD-23 is affecting a process upstream from degradation, such as ubiquitination. We examined total ubiquitinated protein in hR23Aand hR23B-null MEFs and found no difference from WT MEFs. However, there was likely an increased flux of ubiquitinated substrates through the proteasome in hR23A- and hR23B-null MEFs
(Fig. 11D) based on the observation that inhibiting the proteasome with MG-132 led to a greater accumulation of nondegraded ubiquitinated substrates in RAD-23-null MEFs compared with WT MEFs. Next, we determined the ubiquitination status of wtTDP-43 and mutTDP-43 following RAD-23 knockdown in HEK293 cells. By immunoprecipitating myc-tagged wtTDP-43 and immunoblotting for ubiquitin, we found that knockdown of neither $h R 23 A$ nor $h R 23 B$ substantially affected the steady-state abundance of ubiquitinated wtTDP-43 (Fig. 11E); this is comparable to what was found for the turnover rate of wtTDP-43 following RAD-23 knockdown in HEK293 cells (Fig. 9D). In contrast, when myc-tagged mutTDP-43 was immunoprecipitated, we found an increase in the steady-state abundance of ubiquitinated mutTDP-43 (Fig. 11F) in lysates from $h R 23 A$ or $h R 23 B$-knocked down cells compared with control cells. We also examined ubiquitination of mutTDP-43 \pm MG-132 to estimate flux of the ubiquitinated substrates through the proteasome. We found that the MG-132 induction ratio of polyubiquitinated mutTDP-43 was increased following RAD-23 knockdown by $50 \%$ compared with control (Fig. 11G-I). This suggests that the increased level of polyubiquitinated mutTDP-43 correlates with increased flux through the proteasome. In sum, these data suggest that hR23A and 


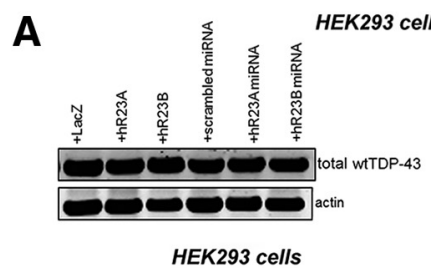

D

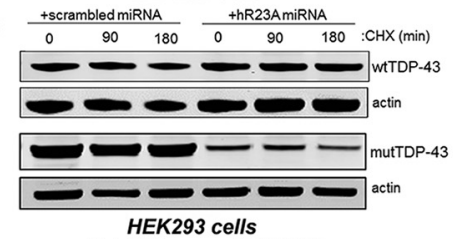

$\mathbf{F}$

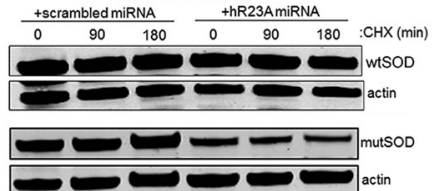

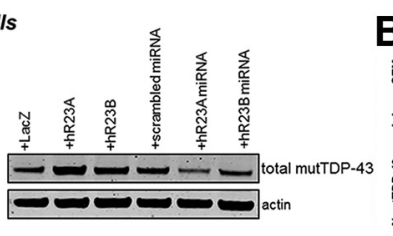

E

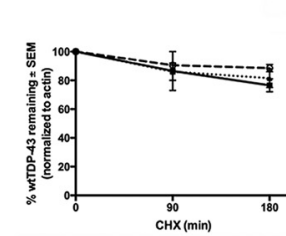

G

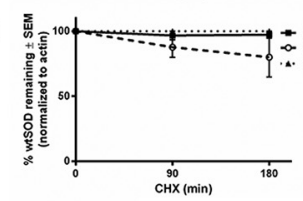

B HEK293 cells

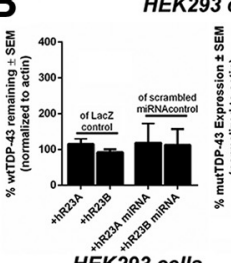

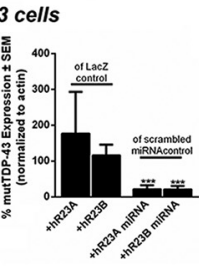

C

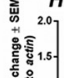<smiles>[AlH2]</smiles>

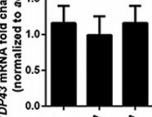<smiles>C1=CCCCC1</smiles>

HEK293 cells

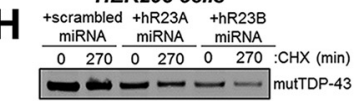
$-\infty-0-1$ actin

I
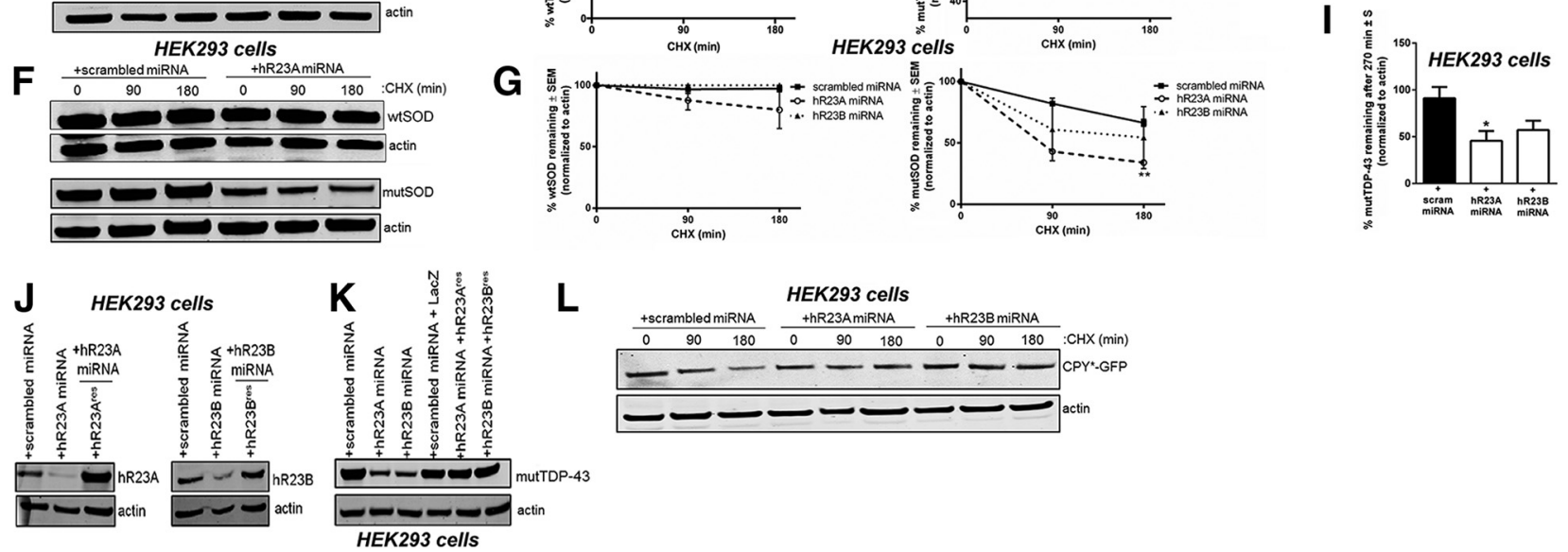

HEK293 cells

Figure 9. Manipulations of RAD-23 expression change TDP-43 and SOD1 abundance and solubility. A, Representative Western blots of the total amount of wtTDP-43 and mutTDP-43 following overexpression or knockdown of $h$ R23A or hR23B. B. The quantification of the amount of total wtTDP-43 or mutTDP-43 following overexpression or knockdown of $h R 23 \mathrm{~A}$ or $h R 23 B$. There is an $\sim 90 \%$ decrease $(p<0.005)$ in the abundance of mutTDP-43 following knockdown of $h R 23 A$ or $h R 23 B$. C, There is no change in the amount of $h T D P-43$ mRNA normalized to actin in HEK293 cells following $h R 23 A$ or $h R 23 B$ knockdown ( $n=3 /$ group). $h T D P-43$ mRNA from untransfected cells was subtracted from all values. $D$, Representative Western blots of wtTDP-43 or mutTDP-43 expression for the indicated time points following $C H X$ treatment with either a control or $h R 23 A$ miRNA. $F_{(2,8)}=0.1380 ; p=0.8732$. $E$, Quantification ( $n=4$ independent experiments) of percentage of starting wtTDP-43 or mutTDP-43 remaining. $\boldsymbol{F}$, Representative Western blots of wtSOD1 or mutSOD1 expression for the indicated time points following CHX with either a control or $h R 23 A$ miRNA. $\boldsymbol{G}$, Quantification ( $n=3$ independent experiments) of percentage of starting wtSOD1 or mutSOD1 remaining. $\boldsymbol{H}, \boldsymbol{I}$, Knockdown of hR23A further reduces percentage of starting mutTDP-43 remaining after $270 \mathrm{~min}$ of CHX ( $n=3$ independent experiments). ${ }^{*} p<0.5$. $\boldsymbol{H}$, Representative Western blot and $(\boldsymbol{I})$ quantification of mutTDP-43 remaining after 270 min of $\mathrm{CHX}$ in the presence of the

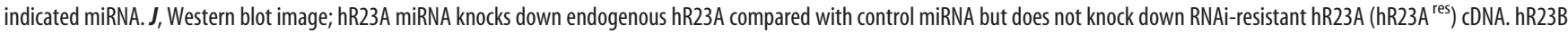
miRNA knocks down endogenous hR23B compared with control miRNA but does not knock down RNAi-resistant hR23B (hR23B res) CDNA. $K$, Cotransfection of an hR23A or hR23B miRNA dramatically decreases total mutTDP-43 protein compared with control. This is blocked by cotransfection with hR23A ${ }^{\text {res }}$ or hR23B ${ }^{\text {res }}$ CDNA. L, Representative Western blot of CPY*-GFP expression for the indicated time points following CHX treatment with indicated miRNA. ${ }^{*} p<0.05$ (Student's $t$ test). ${ }^{* *} p<0.01$ (Student's $t$ test).

A

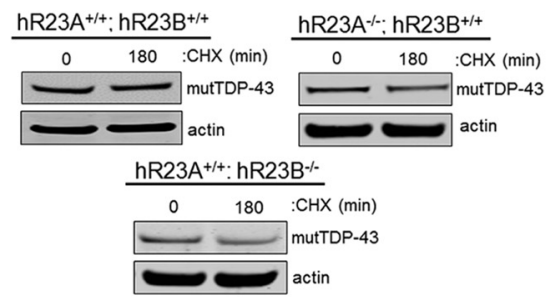

C

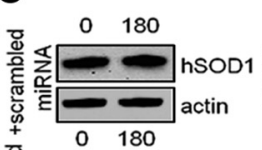

rat neurons

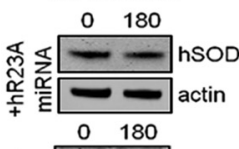

actin
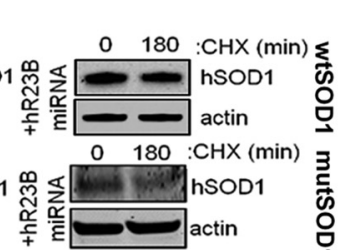

B

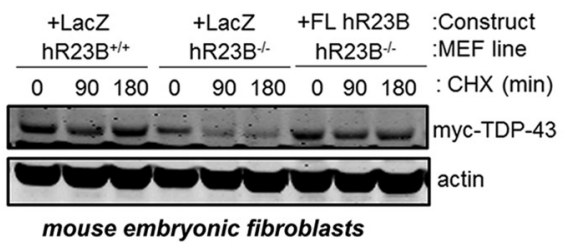

D

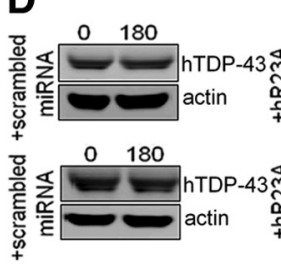

Figure 10. Reducing R23 abundance accelerates SOD1 and TDP-43 turnover in MEFs and primary spinal cord neurons. A, Amount of mutTDP-43 remaining is reduced after 180 min of CHX in hR23A- and hR23B-null MEFs compared with WT. B, WT or hR23B-null (hR23B ${ }^{-1-}$ ) MEFs were cotransfected with mutTDP-43 construct and LacZ or full-length (FL) hR23B construct. Media was changed $24 \mathrm{~h} \mathrm{later}$, and cells were replated at equal densities another $24 \mathrm{~h} \mathrm{later}$. CHX was then added $24 \mathrm{~h}$ after replating for the indicated periods of time. Samples were processed for Western blot and probed with myc and actin antibodies. C, Representative Western blot of wtSOD1 and mutSOD1 abundance in neurons after 0 and 180 min of CHX. Mixed rat spinal cord culture neurons were infected with HSV to express wtSOD1 or mutSOD1 along with HSV expressing the $h R 23 A, h R 23 B$, or control miRNA. D, Representative Western blot of wtTDP-43 and mutTDP-43 abundance in neurons after 0 and 180 min of CHX. Mixed rat spinal cord culture neurons were infected with HSV to express wtTDP-43 or mutTDP-43 along with HSV expressing the $h R 23 A, h R 23 B$, or control miRNA. 

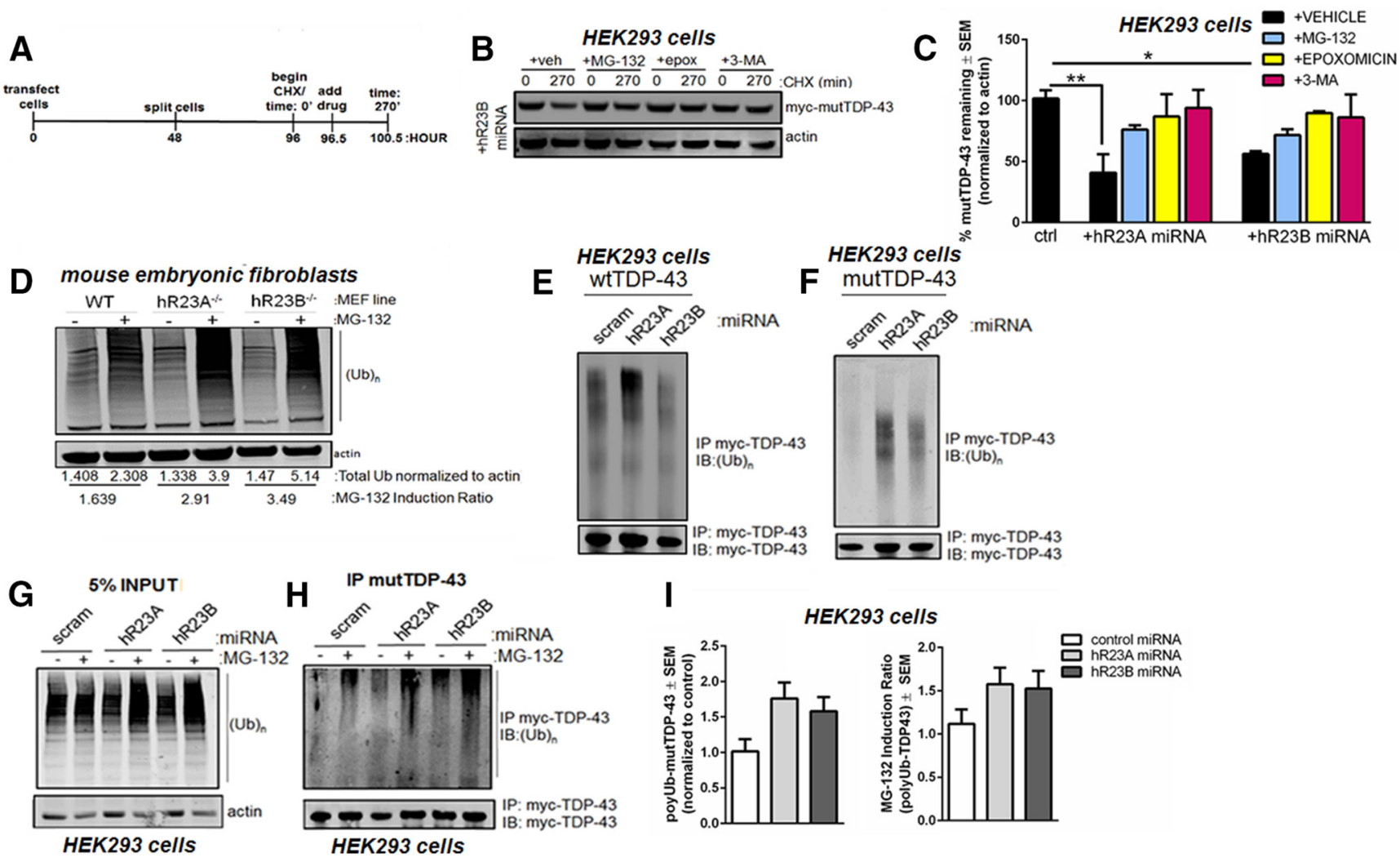

Figure 11. Inhibition of the proteasome and autophagy blocks the enhanced clearance of mutTDP-43 by loss of RAD-23. A, Timeline of CHX experiment performed with inhibitors. HEK293 cells were transfected with mutTDP-43 and $h R 23 A, h R 23 B$, or control miRNA. CHX was added for $4.5 \mathrm{~h}$ and indicated drug was added 30 min after CHX. B, Representative Western blots for $+h R 23 B$ miRNA experiment. Treatment with MG-132, epoxomicin, or 3-MA blocks the clearance of mutTDP-43 seen after 270 min of CHX treatment in the vehicle (DMSO) group. C, Quantification of Western blots. Treatment with MG-132, epoxomicin ("epox"), and 3-MA blocked the turnover of mut-TDP43 by $\sim 25 \% . n=5$ independent experiments for + scrambled miRNA; $n=3$ independent experiments for + hR23A miRNA; $n=3$ independent experiments for + hR23B miRNA. $F_{(8,20)}=3.156 ; p=0.0176 .{ }^{*} p<0.05 .{ }^{* *} p<0.01$. D. Total polyubiquitinated (polyUb) substrate load in indicated MEF lines following - MG-132 (DMSO) or + MG-132 treatment for 12 h. MG-132 induction ratio: + MG-132/-MG-132 (all normalized to actin). E, $F$, Representative Western blot of polyUb-mutTDP-43 following immunoprecipitation (IP) of myc-wtTDP-43 (E) or myc-mutTDP-43 (F) in HEK293 cells cotransfected with $h R 23 A, h R 23 B$, or control miRNA. Knockdown of $h R 23 A$ or $h R 23 B$ inhibits the ubiquitination of mutTDP-43 but has no effect on the ubiquitination status of wtTDP-43. G, Representative Western blot showing total polyUb-load in HEK293 cells transfected with mutTDP-43 and indicated miRNA. Cells were treated with DMSO ( - MG-132) or MG-132 (+ MG-132) $12 \mathrm{~h}$ before cell lysis as indicated. $\boldsymbol{H}$, Myc-mutTDP-43 was immunoprecipitated and immunoblotted for ubiquitin and myc; representative Western blot is shown. $\boldsymbol{I}$, Quantification ( $n=3$ independent experiments) of Western blots shown in $\boldsymbol{H}$. Data were normalized to average + control miRNA condition. There is an increase in ubiquitinated mutTDP-43 and its flux through the proteasome following RAD-23 knockdown.

hR23B can inhibit the ubiquitination of mutTDP-43 in HEK293 cells and hinder its proteasomal degradation.

\section{Loss of rad-23 decreases mutTDP-43 and mutSOD1 insolubility}

Because TDP-43 inclusions are made up of insoluble TDP-43 aggregates, we investigated the effect of reducing RAD-23 on TDP-43 solubility in vivo and in vitro. In C. elegans, we found that loss of rad-23 resulted in a decrease of total insoluble TDP-43 (Fig. 12A). In addition, we detected a decrease in phospho-TDP-43 levels in $C$. elegans in the loss of rad-23 background (Fig. 12B) and phosphoTDP-43 has been implicated as the toxic species in ALS (Neumann et al., 2009). To determine whether this effect was specific to mutTDP-43 in C. elegans, we also measured total wtTDP-43 protein abundance in WT and rad-23 animals. We found no change in the amount of total wtTDP-43 in loss of rad-23 animals compared with WT (Fig. 12C), which was consistent with the observation that loss of rad-23 had no effect on wtTDP-43 locomotion. In HEK293 cells, we found that overexpression of hR23A increased the insolubility of mutTDP-43 (Fig. 12D). We also measured hTDP43 mRNA abundance in hTDP43-expressing C. elegans in WT and loss of rad-23 backgrounds. We found a significant increase in $h T D P-43 \mathrm{mRNA}$ compared with WT in the loss of rad-23 background (Fig. 12E).
These data are consistent with the known negative autoregulation of TDP-43 on its mRNA (Polymenidou et al., 2011; AvendandoVasquez et al., 2012).

To test our hypothesis that the other suppressors identified in our candidate gene approach were via additive pathways, we examined the ability of loss of $u f d-2(\mathrm{tm} 1380)$ to reduce mutTDP-43 abundance on its own and in combination with loss of rad-23. We found that loss of $u f d-2(t m 1380)$ also reduced mutTDP-43 protein abundance and the abundance of phosphorylated mutTDP-43 in C. elegans, although the effect was smaller than loss of rad-23 (tm3690). Meanwhile, in triple mutant animals (mutTDP-43; ufd-2 (tm1380); rad-23 (tm3690)), there was an additive effect on reducing the abundance of mutTDP-43 and phosphorylated mutTDP-43, which was greater than what was seen in the single mutant backgrounds (Fig. 12F). Consistent with this finding, loss of $u f d-2$ was recently identified in a genetic screen as a suppressor of mutSOD1 and mutTDP- 43 toxicity by regulating protein quality control (Periz et al., 2015).

The correctly folded conformation of a protein is in equilibrium with multiple misfolded conformations, and these later species are prone to aggregate into oligomers and higher-order structures. The dwell time of misfolded conformations is a function of the free energy barriers between states and generally in- 

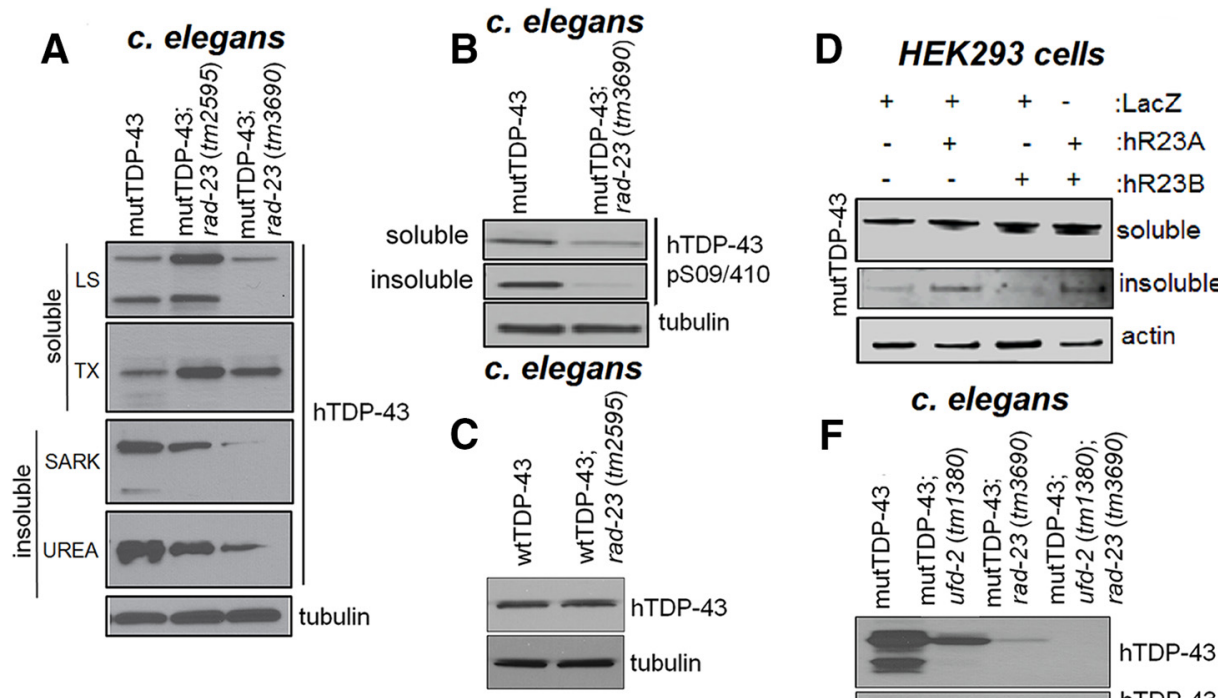

c. elegans

$\mathbf{F}$

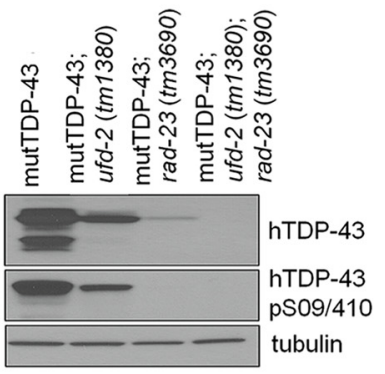

c. elegans

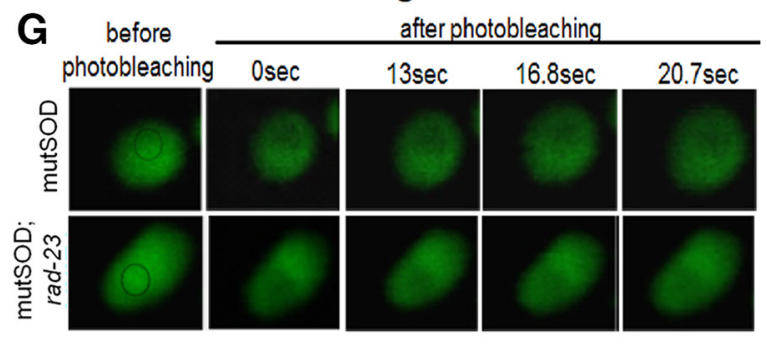

E

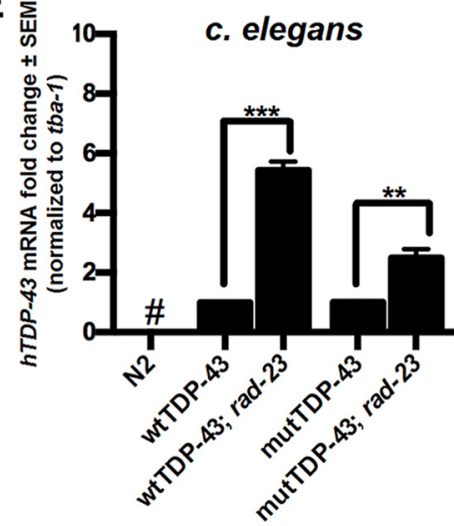

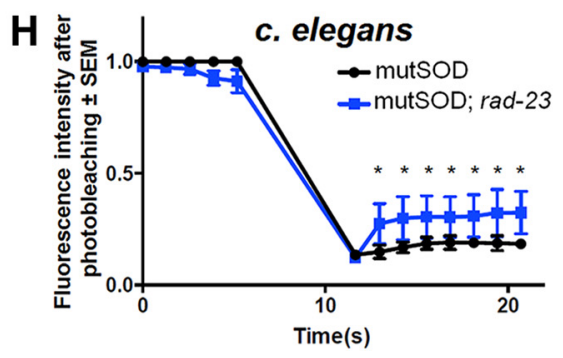

Figure 12. Loss of rad-23 reduces TDP-43 and SOD1 insolubility. A, Representative Western blot of hTDP-43 protein abundance following a sequential detergent extraction of $C$. elegans overexpressing mutTDP-43 in WT or rad-23 backgrounds. Loss of rad-23 causes a shift of TDP-43 to a more soluble (TX) fraction over insoluble (SARK, UREA) fractions. $\boldsymbol{B}$, There is a decrease of phospho-TDP-43 in the loss of rad-23 background in soluble and insoluble fractions in C. elegans. C, Total wtTDP-43 levels are indistinguishable in the loss of rad-23 (tm3690) background compared with the control WT TDP-43 background in C. elegans. D, Representative Western blot showing that there is an increase in the abundance of insoluble mutTDP-43 in HEK293 cells following cotransfection with the hR23A cDNA. E, qPCR ( $n=3 /$ group) measuring $h T D P-43$ mRNA abundance normalized to tba- 1 in indicated C. elegans strains. ${ }^{*}$ Undetected. ${ }^{* *} p<0.01 .{ }^{* * *} p<0.01$. $\boldsymbol{F}$, Rad-23 (tm3690) and ufd-2 (tm 1380) cause an additive effect in reducing mutTDP-43 and phosophorylated-TDP43 abundance in C. elegans. G, H, FRAP on mutSOD1-YFP aggregates within the $C$. elegans nervous system. mutSOD1-YFP has a higher rebound with loss of rad-23 (tm3690). G, Representative images of FRAP assay. $\boldsymbol{H}$, Quantification of FRAP $\left(n=14 /\right.$ group). ${ }^{*} p<0.05$. Data are normalized to starting fluorescence intensity.

creases as aggregates form (Fawzi et al., 2008). This can be probed by examining the FRAP of fluorescently tagged misfolding-prone proteins. Misfolded proteins become less mobile within cells and have a slower recovery time following photobleaching (J. Wang et al., 2009; Scotter et al., 2014). We examined the ability of mutSOD1 tagged with YFP in the C. elegans nervous system to recover following photobleaching in WT and loss of rad-23 backgrounds in vivo. Loss of rad-23 allowed for increased recovery of YFPtagged mutSOD1 over WT (Fig. 12G,H; $p<0.05$ ). These data indicate that loss of rad-23 leads to an increase in the pool of readily exchangeable and mobile mutSOD1. In sum, loss of rad-23 leads to a decrease of soluble and insoluble species, as well as a reduction in the toxic phosphorylated TDP-43 species.

\section{hR23A and hR23B are aberrantly expressed in human ALS spinal cord}

Changes in the abundance of RAD-23 could have pathophysiological relevance to human ALS. A single nucleotide polymorphism was found to be correlated with changes in hR23A expression (Myers et al., 2007), and the same single nucleotide polymorphism was found to be associated with sporadic ALS (Cronin et al., 2007). In addition, a microarray study found that $h R 23 A$ expression was increased in postmortem fALS spinal cord tissue compared with controls (Dan- gond et al., 2004). To directly implicate our findings to the human condition, we compared $\mathrm{hR} 23 \mathrm{~A}$ and $\mathrm{hR} 23 \mathrm{~B}$ expression and localization in the spinal cords of sALS and fALS cases with spinal cords from non-neurodegenerative disease controls.

We found several alterations in the expression pattern of $h R 23 \mathrm{~A}$ and hR23B in ALS tissue (Fig. 13A-C; Tables 4, 5). hR23A and $\mathrm{hR} 23 \mathrm{~B}$ accumulated in deposits within the cytoplasm of motor neurons in both sALS and fALS cases (Fig. 13B). In addition, hR23A and hR23B tended to accumulate in the nucleus more robustly in ALS cases than in controls (Fig. 13B). We also found substantially greater protein abundance of hR23A $(p<0.05)$ and hR23B $(p<0.01)$ in ALS spinal cord tissue (Fig. 13C) compared with controls. Together, these data indicate that there is a mislocalization and accumulation of RAD-23 in human ALS pathology.

\section{Discussion}

We show that reducing RAD-23 abundance protects against the toxicity of two misfolding-prone proteins that cause ALS. Mechanistically, this is linked to increased mobility, accelerated degradation, and reduced steady-state levels of the toxic proteins (Fig. 13D). This is likely to be directly relevant to the human condition because we detect increased levels of RAD-23 in postmortem ALS spinal cord samples and RAD-23 
A

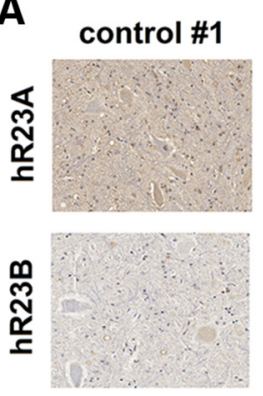

B

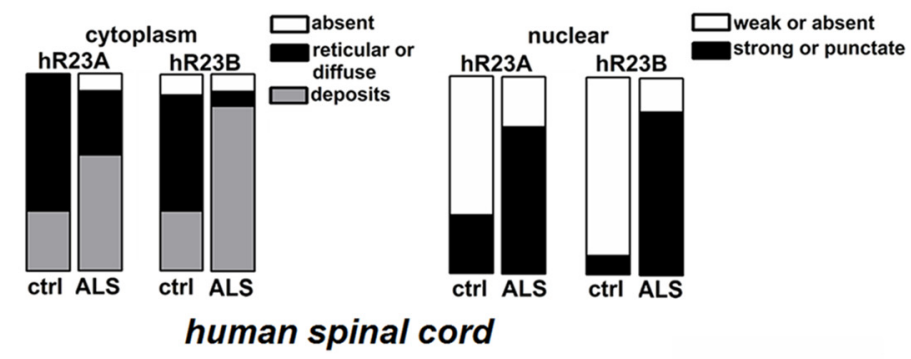

human spinal cord
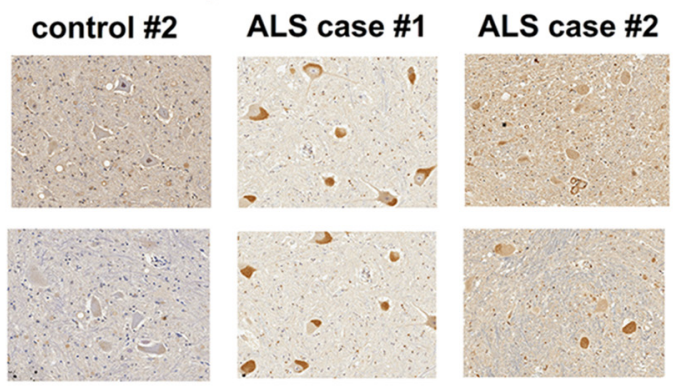

D
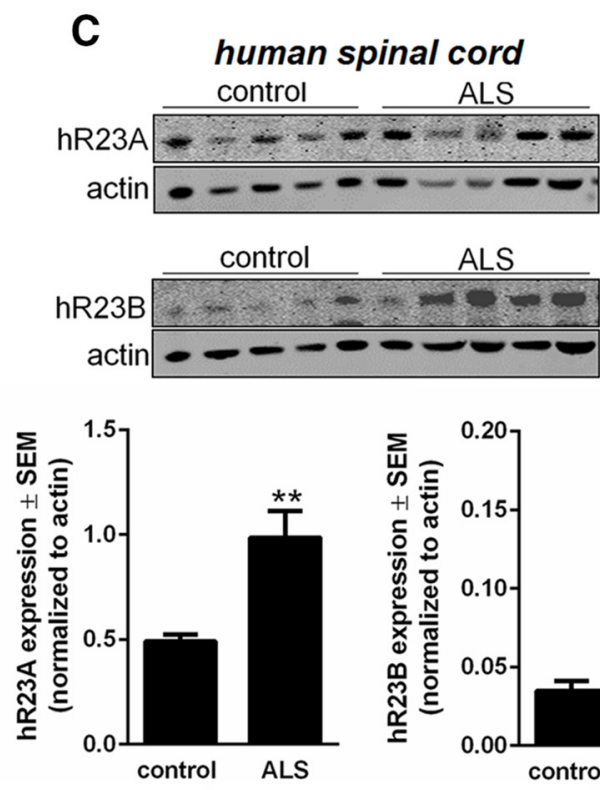

human spinal cord

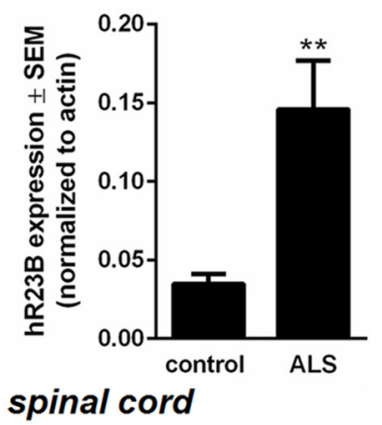

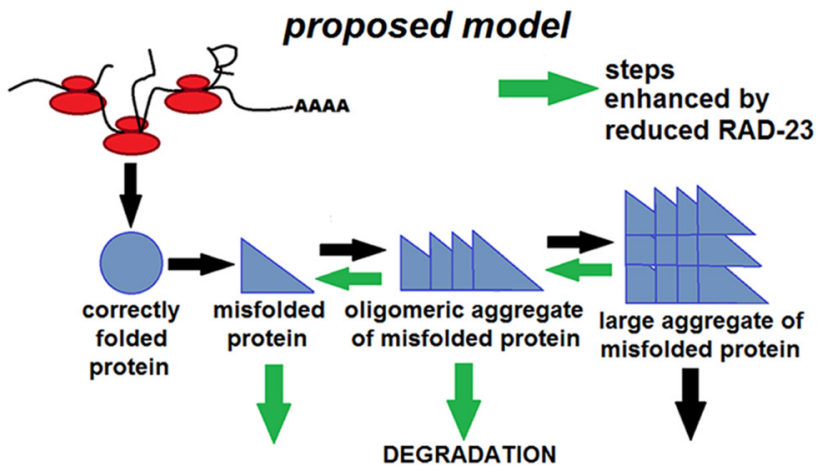

Figure 13. hR23A and hR23B are aberrantly expressed in human ALS tissue. $A, B$, There is mislocalization of $h R 23 A$ and $h R 23 B$ in motor neurons of the spinal cord in ALS cases. $A$, Representative images of motor neurons within the gray matter of spinal cord from control and ALS cases. Insets within ALSCase 2, Granular cytoplasmic and nuclear staining often found in ALS cases. $B$, Distribution of hR23A and hR23B cytoplasm and nuclear staining found in control $(n=9)$ and ALS cases $(n=12)$. C, There is an increase in hR23A and hR23B protein expression in ALS $(n=5)$ spinal cord sections compared with controls $(n=5) .{ }^{* *} p<0.01$ (Student's $t$ test). $\boldsymbol{D}$, Proposed model. Loss of rad-23 destabilizes aggregates, allowing them to become more soluble and more easily degraded.

is mislocalized in ALS motor neurons. Elevated RAD-23 levels lead to the accumulation of misfolded conformers likely by inhibiting their polyubiquitination (or ubiquitin remodeling) and preventing their clearance through protein degradation pathways. These observations highlight the role of native proteins that modify the ubiquitination status of toxic proteins in human neurodegenerative disease.

RAD-23 was originally identified in yeast in a screen for genes that influence sensitivity to UV irradiation (Watkins et al., 1993). Subsequent work demonstrated that RAD-23 plays a critical role in protein homeostasis (Schauber et al., 1998). A unified picture of RAD-23 function in protein turnover has not emerged, however, because of the following: (1) the diversity of platforms used to interrogate its function (purified proteasomes, yeast, mammalian cells) (Table 6); (2) the variety of studied substrates (i.e., reporters, such as ubiquitin fusion degradation substrates and various physiological clients) (Table 6); and (3) the recognition that the biological function of RAD-23 is exquisitely controlled by its expression level and the stoichiometry with other proteins of the UPS (Verma et al., 2004). Even when controlling for these factors, it is clear that endogenous RAD-23 accelerates the degradation of some substrates and stabilizes the abundance of other substrates (Table 6) (Lambertson et al., 1999; Ortolan et al., 2000, 2004; Rao and Sastry, 2002; Ng et al., 2003; Raasi and Pickart, 2003; Brignone et al., 2004; Kim et al., 2004; Verma et al., 2004; Bacopulus et al., 2012). The features that distinguish these substrates are unknown.

The domain structure of RAD-23 implies a mechanism for its operation as a "shuttle factor." The RAD-23 ubiquitin-associated domain binds to ubiquitin chains of client proteins (Chen et al., 2001; Wilkinson et al., 2001; Chen and Madura, 2006; Ryu et al., 2013) and brings them to the proteasome via the interaction of the RAD-23 ubiquitin-like domain and RPN-10, a subunit of the 19 cap of the proteasome (Schauber et al., 1998; van Laar et al., 2002). In parallel with this activity, RAD-23 also acts as a protein stabilization factor by binding polyubiquitin chains of specific lengths and blocking further chain elongation and/or remodeling, events required for efficient client degradation (Raasi and Pickart, 2003). RAD-23 was shown to stabilize the NER factor, RAD-4, in yeast and mammals by inhibiting its ubiquitination (Lommel et al., 2002; Ng et al., 2003), and RAD-23 can also 
Table 4. Description of human ALS cases used for staining and expression analysis ${ }^{a}$

\begin{tabular}{|c|c|c|c|c|c|c|c|c|c|}
\hline ALS & SALS or fALS & Case description & $\begin{array}{l}\text { Age } \\
(\mathrm{yr}) / \mathrm{sex}\end{array}$ & $\begin{array}{l}\text { Approximate } \\
\text { symptom duration } \\
\text { (mo) }\end{array}$ & $\begin{array}{l}\text { Autopsy } \\
\text { interval } \\
\text { (h) }\end{array}$ & $\begin{array}{l}\text { hR23A cytoplasm } \\
\text { pattern }\end{array}$ & $\begin{array}{l}\text { hR23A nucleus } \\
\text { pattern }\end{array}$ & $\begin{array}{l}\text { hR23B cytoplasm } \\
\text { pattern }\end{array}$ & $\begin{array}{l}\text { hR23B nucleus } \\
\text { pattern }\end{array}$ \\
\hline \multicolumn{10}{|l|}{ Case } \\
\hline JH83 & fALS & $\begin{array}{l}\text { SOD1 N193K Onset: } \\
\text { left leg }\end{array}$ & $50 / M$ & 74 & 14.5 & Strong deposits & Strong staining & Strong deposits & Punctate staining \\
\hline $\mathrm{JH} 43$ & fALS & $\begin{array}{l}\text { SOD1 A4V Onset: } \\
\text { LE/left leg }\end{array}$ & $55 / M$ & 21 & Unknown & Reticular & Punctate staining & Weak deposits & Strong staining \\
\hline $\begin{array}{l}\text { JH74 (ALS Case } 2 \\
\text { in Fig. 12) }\end{array}$ & fALS & $\begin{array}{l}\text { SOD1 A4V } \\
\text { Bulbar onset }\end{array}$ & $47 / M$ & 15 & 18.5 & $\begin{array}{l}\text { Strong and weak } \\
\text { deposits }\end{array}$ & Strong staining & $\begin{array}{l}\text { Strong and weak } \\
\text { deposits }\end{array}$ & Punctate staining \\
\hline $\mathrm{JH} 82$ & SALS & Onset: LE/left leg & $66 / M$ & 43 & 13 & Absent & Strong staining & Weak deposits & Punctate staining \\
\hline $\mathrm{JH} 73$ & SALS & $\begin{array}{l}\text { Onset: LE/left } \\
\text { foot }\end{array}$ & $70 / F$ & 36 & 8 & Strong deposits & Strong staining & $\begin{array}{l}\text { Punctate and strong } \\
\text { deposits }\end{array}$ & Strong staining \\
\hline JH86 & $\begin{array}{l}\text { FTD + fALS } \\
\quad(\text { C90RF72+) }\end{array}$ & $\begin{array}{l}\text { Onset: legs/ } \\
\text { cognition }\end{array}$ & $74 / M$ & $\sim 84$ & 32 & Strong deposits & Strong staining & Strong deposits & Weak staining \\
\hline JH79 & SALS & Bulbar onset & $70 / F$ & 28 & 12 & Strong deposits & Strong staining & Strong deposits & Strong straining \\
\hline $\mathrm{JH} 22$ & fALS (C90RF72+) & $\begin{array}{l}\text { Onset: UE/left } \\
\text { arm }\end{array}$ & $66 / M$ & 22 & 6 & Punctate throughout & Punctate staining & Absent & Strong staining \\
\hline $\mathrm{JH} 49$ & SALS & $\begin{array}{l}\text { Onset: UE/right } \\
\text { hand }\end{array}$ & $68 / \mathrm{F}$ & 70 & 4 & $\begin{array}{l}\text { Strong and weak } \\
\text { deposits }\end{array}$ & Weak staining & Weak deposits & Punctate staining \\
\hline $\mathrm{JH} 88$ & $\begin{array}{l}\text { FTD + fALS } \\
\quad(\text { C90RF72+) }\end{array}$ & Bulbar onset & $59 / \mathrm{M}$ & 20 & 10 & Reticular & Weak staining & $\begin{array}{l}\text { Strong and weak } \\
\text { deposits }\end{array}$ & Weak staining \\
\hline $\begin{array}{l}\text { JH07 (ALS Case } 1 \\
\text { in Fig. 12) }\end{array}$ & SALS (C90RF72+) & Bulbar onset & $67 / M$ & 14 & 8 & Strong deposits & Weak staining & Strong deposits & Strong staining \\
\hline $\mathrm{JH} 80$ & sALS & Onset: UE (right) & $56 / F$ & 50 & 21 & Strong deposits & Punctate staining & $\begin{array}{l}\text { Strong and weak } \\
\text { deposits }\end{array}$ & Punctate staining \\
\hline
\end{tabular}

${ }^{a}$ The 12 ALS cases from which postmortem spinal cord tissue was taken following autopsy. UE, Upper extremities; LE, lower extremities; SALS, sporadic ALS; fALS, familial ALS (i.e., positive family history). ALS cases in Figure 12C were loaded in Western blot in this order: JH79, JH82, JH74, JH74, JH83.

Table 5. Description of control cases used for staining and expression analysis ${ }^{a}$

\begin{tabular}{|c|c|c|c|c|c|c|c|}
\hline Control case & Age (yr)/sex & Cause of death & $\begin{array}{l}\text { Autopsy } \\
\text { interval }\end{array}$ & hR23A cytoplasm pattern & hR23A nucleus pattern & hR23B cytoplasm pattern & $\begin{array}{l}\text { hR23B nucleus } \\
\text { pattern }\end{array}$ \\
\hline $\begin{array}{l}23 \text { (Control Case } 2 \\
\text { in Fig. 8) }\end{array}$ & $77 / M$ & Cardiac failure & $6 \mathrm{~h}$ & Diffuse & Light staining & Absent & Absent \\
\hline 31 & $67 / M$ & Lung cancer & $3.5 \mathrm{~h}$ & Deposits & Absent & Weak deposits & Absent \\
\hline 37 & $57 / \mathrm{M}$ & $\begin{array}{l}\text { Cardiac arrest due to } \\
\text { ventricular fibrillation }\end{array}$ & $14 \mathrm{~h}$ & Deposits & Some light nuclear staining & $\begin{array}{l}\text { Diffuse throughout and } \\
\text { scattered }\end{array}$ & Absent \\
\hline 44 & $80 / F$ & Liver failure & $5 \mathrm{~h}$ & Some weak deposits & Light staining & Reticular & Absent \\
\hline 65 & $82 / M$ & Unknown & $4 \mathrm{~h}$ & Reticular & Present & Diffuse and reticular & Absent \\
\hline 67 & $77 / M$ & Unknown & $4 \mathrm{~h}$ & Reticular & Present & Deposits & Strong staining \\
\hline $\begin{array}{l}78 \text { (Control Case } 1 \\
\text { in Fig. 8) }\end{array}$ & $58 / \mathrm{F}$ & $\begin{array}{l}\text { Vasculitis, cerebral } \\
\text { hemorrhage, hepatitis C }\end{array}$ & $3 \mathrm{~h}$ & Reticular & Absent & Reticular & Absent \\
\hline
\end{tabular}

${ }^{a}$ The 9 control cases from which postmortem spinal cord tissue was taken following autopsy. Control Case 1 in Figure $12 \mathrm{~A}$ was 78 and Control Case 2 in Figure $12 \mathrm{~A}$ was 23 . Control cases in Figure $12 \mathrm{C}$ were loaded in Western blot in this order: $6,23,67,31,26$.

prevent the clearance of other disease-related proteins (Blount et al., 2014).

The toxicity of TDP-43 and other misfolding-prone proteins is related to the abundance of the proteins on a per-cell basis with increased abundance linked to increased toxicity (Barmada et al., 2014). Because mutTDP-43 levels are reduced in RAD-23 knockdown or null cells, this observation readily accounts for the beneficial effects of targeting RAD-23. Mechanistically, we find increased steady-state levels of ubiquitinated mutTDP-43 in RAD-23 knockdown cells, and this is associated with enhanced flux through the clearance pathways. This agrees with studies following the increased degradation of the reporter substrate $\mathrm{Ub}^{\mathrm{V} 96} \mathrm{~V}-\mathrm{V}$ - gal in yeast lacking rad-23 (Rao and Sastry, 2002) and other studies showing that overexpression of RAD-23 can inhibit ubiquitin chain elonga- tion (Ortolan et al., 2000, 2004). In addition, we found that inhibition of autophagy and the proteasome blocked the turnover of ubiquitinated mutTDP-43, and this is in line with work using other aggregation-prone proteins (Lu et al., 2014). Whether or not RAD-23 directly stimulates the flux of mutTDP-43 and other proteins through autophagy remains to be determined. Of note to this work, HDAC6 was previously found to be in a negative regulator of hR23B. The ability of HDAC6 inhibition to increase the rate of autophagy was found to rely on the level of hR23B expression within the cell. Cells with low hR23B expression were found to have increased rates of autophagy following HDAC6 inhibition, whereas cells with higher hR23B expression were found to be more likely to initiate apoptosis following HDAC6 inhibition (New et al., 2013). 
Table 6. RAD-23 has opposing roles on substrate stabilization ${ }^{a}$

\begin{tabular}{|c|c|c|c|c|}
\hline Substrate & RAD-23 manipulation & Effect on substrate & Platform & Reference \\
\hline $\operatorname{Arg}-\beta$-Gal & Overexpression & Stabilizes & Yeast & Ortolan et al., 2000 \\
\hline Rad-4 & Overexpression & Stabilizes & Yeast & Ortolan et al., 2004 \\
\hline Ub-Pro- $\beta$-Gal & Overexpression & Stabilizes & Yeast & Ortolan et al., 2000 \\
\hline Lactalbumin & Replacement & Stabilizes & Ub-depleted reticulocyte extract & Raasi and Pickart, 2003 \\
\hline $\mathrm{Ub}_{5}$-DHFR & Replacement & Stabilizes & HEK293T cells & Raasi and Pickart, 2003 \\
\hline $\mathrm{BCA2}$ & Overexpression & Stabilizes & U202 and H1299 cells & Bacopulus et al., 2012 \\
\hline p53 & Overexpression & Stabilizes & U202 cells & Brignone et al., 2004 \\
\hline p53 & Loss of function (hR23A and hR23B) & Destabilizes & U202 cells & Brignone et al., 2004 \\
\hline Ub-Pro- $\beta$-Gal & Loss of function & Stabilizes & $\Delta$ rad23 yeast & Lambertson et al., 1999 \\
\hline $\mathrm{Ub}^{\mathrm{V} 76}-\mathrm{V}-\beta$-gal & Loss of function & Stabilizes & $\Delta$ rad23 yeast & Rao et al., 2002; Kim et al., 2004 \\
\hline Sic1 & Replacement & Destabilizes & Proteasomes purified from $\Delta$ rad 23 yeast & Verma et al., 2004 \\
\hline Far1 & Loss of function & Stabilizes & $\Delta$ rad23 yeast & Verma et al., 2004 \\
\hline
\end{tabular}

${ }^{a}$ Summary of past findings on RAD-23 manipulation and substrate turnover.

RAD-23 interacts, directly or indirectly, with a number of proteins that control ubiquitination and degradation of client proteins, including the deubiquitinase ataxin-3 (Boeddrich et al., 2006; Zhong and Pittman, 2006; Morreale et al., 2009), the unfoldase VCP (Buchberger et al., 2010), and the autophagy machinery component, p62 (Yokoi et al., 2000). There are at least two intriguing implications that follow from these observations. First, mutations in each of these RAD-23 interactors lead to the accumulation of misfolded proteins and neurodegeneration. This raises the possibility that RAD-23 may contribute to the diseases evoked by these mutated proteins, and we are aware of a single instance where this has been demonstrated. Polyglutamine (polyQ-) expansion in ataxin-3 causes spinocerebellar atrophy Type 3 , and the ubiquitin-binding site 2 at the $\mathrm{N}$ terminus of ataxin-3 binds to RAD-23. Disrupting this interaction, or knocking down RAD-23, reduces ataxin-3 levels and mitigates the toxicity of polyQ-expanded ataxin-3 (Blount et al., 2014). This example raises the possibility that the toxicity of other RAD-23-binding partners might similarly be modified as we have shown here for mutTDP-43 in a RAD23-dependent manner. Second, fALS can result from mutations in VCP and p62, as well as two other proteins involved in protein homeostasis, optineurin (OPTN) and TANK-binding protein kinase 1 (TBK1) (Wong and Holzbaur, 2014; Cirulli et al., 2015). Although OPTN and TBK1 have no known physical or functional interaction with RAD-23, it is possible RAD-23 may exert its effects through these effectors as well.

Although point mutations in TDP-43 and SOD1 are clearly pathogenic, the role of the WT versions of these proteins in disease is unresolved. Early work from the Cleveland laboratory with the G85R SOD1 mouse indicated that neither overexpression nor knock-out of endogenous mouse SOD1 influenced disease (Bruijn et al., 1998). Subsequent work comes to the opposite conclusion (Jaarsma et al., 2000; Deng et al., 2006; J. Wang et al., 2009). Overexpression of either wtSOD1 (Jaarsma et al., 2000; Graffmo et al., 2013) or wtTDP-43 (Wegorzewska et al., 2009; Wils et al., 2010; Xu et al., 2010, 2011) in mice leads to a neurodegenerative disease phenotype. The participation of endogenous TDP-43 in the disease caused by overexpression of TDP-43 (or SOD1) is unknown and difficult to study because complete elimination of TDP-43 is incompatible with life (Chiang et al., 2010). Recent work by the Zoghbi laboratory demonstrates that the spinocerebellar ataxia Type I phenotype can be evoked by haploinsufficiency of the RNA-binding protein, PUMILIO1 (PUM1) (Gennarino et al., 2015). Loss of PUM1 leads to increased levels of WT ataxin-1. The spinocerebellar ataxia Type I phe- notype elicited by haploinsufficiency of PUM1 is suppressed by normalizing ataxin-1 levels. These observations implicate endogenous WT ataxin-1 in disease, an observation that might point to a broader principle relevant to other neurodegenerative diseases.

We found that overexpression of wtSOD1 or wtTDP-43 was modestly toxic, although less toxic than the mutant proteins, in primary mixed spinal cord neurons. Because increasing levels of WT proteins can be toxic (i.e., SOD1, TDP-43, ataxin-1), our observations are not unprecedented. In some of the experimental platforms used here, loss of rad-23 did not suppress WT protein toxicity (Fig. $2 B-E$ ), whereas in other models it did (see Fig. 7G,H). Loss of rad-23 accelerated the degradation of mutant, but not WT SOD1 and TDP-43 in HEK293 cells (Fig. 9D-J), but accelerated the degradation of both the mutant and WT versions of SOD1 and TDP-43 in primary neurons (Fig. 10C,D). We suspect that some of these discordant observations are linked to the level of WT protein expression. Previously mentioned technical factors are also likely to be in operation. It is possible that loss of rad-23 is protective against the noxious effect of overexpressing wtSOD1 or wtTDP-43 by a mechanism that is distinct from the way loss of rad-23 protects against the noxious effect of overexpressing mutSOD1 or mutTDP-43. It is worth noting that wtSOD1 and mutSOD1 can both share an aberrant conformation (Bosco et al., 2010). Future work will be needed to understand the stoichiometric relationships between the WT and mutant proteins, as well as between RAD-23 and neurodegeneration. In addition, it is possible that RAD-23 may exert different effects on client substrates based on the cellular context or model organism being deployed.

Based on the work presented, we hypothesize that endogenous RAD-23 binds to a select population of ubiquitinated substrates and impedes their degradation by controlling the remodeling of ubiquitin chains. In the absence of RAD-23, ubiquitin chain maturation is unleashed and substrate flux is enhanced (Lambertson et al., 1999; Verma et al., 2004). This is in accordance with work showing that RAD-23 can inhibit ubiquitin chain expansion (Ortolan et al., 2004). In conclusion, past work has identified RAD-23 proteins as forming inclusions in other neurodegenerative diseases, including Huntington's disease, Parkinson's disease, and several forms of ataxia (Bergink et al., 2006). Together, interventions that reduce the abundance of RAD-23 or its association with specific substrates are predicted to be therapeutic for diseases caused by the accumulation of misfolded proteins. 


\section{References}

Atkin JD, Farg MA, Walker AK, McLean C, Tomas D, Horne MK (2008) Endoplasmic reticulum stress and induction of the unfolded protein response in human sporadic amyotrophic lateral sclerosis. Neurobiol Dis 30:400-407. CrossRef Medline

Austin JA, Wright GS, Watanabe S, Grossman JG, Antonyuk SV, Yamanaka K, Hasnain SS (2014) Disease causing mutants of TDP-43 nucleic acid binding domains are resistant to aggregation and have increased stability and half-life. Proc Natl Acad Sci U S A 111:4309-4314. CrossRef Medline

Avendaño-Vázquez SE, Dhir A, Bembich S, Buratti E, Proudfoot N, Baralle FE (2012) Autoregulation of TDP-43 mRNA levels involves interplay between transcription, slicing, and alternative polyA site selection. Genes Dev 26:1679-1684. CrossRef Medline

Bacopulus S, Amemiya Y, Yang W, Zubovits J, Burger A, Yaffe M, Seth AK (2012) Effects of partner proteins on BCA2 RING ligase activity. BMC Cancer 8:12-63. CrossRef Medline

Barmada SJ, Serio A, Arjun A, Bilican B, Daub, Ando DM, Tsvetkov A, Pleiss M, Li X, Peisach D, Shaw C, Chandan S, Finkbeiner S (2014) Autophagy induction enhances TDP43 turnover and survival in neuronal ALS models. Nat Chem Biol 10:67-85. CrossRef Medline

Bergink S, Severijnen LA, Wijgers N, Sugasawa K, Yousaf H, Kros JM, van Swieten J, Oostra BA, Hoeijmakers JH,Vermeulen W, Willemsen R (2006) The DNA repair-ubiquitin-associated HR23 proteins are constituents of neuronal inclusions in specific neurodegenerative disorders without hampering DNA repair. Neurobiol Dis 23:708-716. CrossRef Medline

Bergink S, Toussaint W, Luijsterburg MS, Dinant C, Alekseev S, Hoeijmakers JH, Dantuma NP, Houtsmuller AB, Vermeulen W (2012) Recognition of DNA damage by XPC coincides with disruption of the XPC-RAD23 complex. J Cell Biol 196:681-688. CrossRef Medline

Blount JR, Tsou WL, Ristic G, Burr AA, Ouyang M, Galante H, Scaglione KM, Todi SV (2014) Ubiquitin-binding site 2 of ataxin-3 prevents its proteasomal degradation by interacting with Rad23. Nat Commun 5:e4638. CrossRef Medline

Boeddrich A, Gaumer S, Haacke A, Tzvetkov N, Albrecht M, Evert BO, Müller EC, Lurz R, Breuer P, Schugardt N, Plassmann S, Xu K, Warrick JM, Suopanki J, Wüllner U, Frank R, Hartl UF, Bonini NM, Wanker EE (2006) An arginine/lysine-rich motif is critical for VCP/p97-mediated modulation of ataxin-3 fibrillogenesis. EMBO J 25:1547-1558. CrossRef Medline

Böhm S, Lamberti G, Fernández-Sáiz V, Stapf C, Buchberger A (2011) Cellular functions of Ufd2 and Ufd 3 in proteasomal protein degradation depend on Cdc48 binding. Mol Cell Biol 31:1528-1539. CrossRef Medline

Bosco DA, Morfini G, Karabacak NM, Song Y, Gros-Louis F, Pasinelli P, Goolsby H, Fontaine BA, Lemay N, McKenna-Yasek D, Frosch MP, Agar JN, Julien JP, Brady ST, Brown RH Jr (2010) Wild-type and mutant SOD1 share an aberrant conformation and a common pathogenic pathway in ALS. Nat Neurosci 13:1396-1403. CrossRef Medline

Brenner S (1974) The genetics of Caenorhabditis elegans. Genetics 1:71-94. Medline

Brignone C, Bradley KE, Kisselev AF, Grossman SR (2004) A postubiquitination role for MDM2 and hHR23A in the p53 degradation pathway. Oncogene 23:4121-4129. CrossRef Medline

Bruijn LI, Houseweart MK, Kato S, Anderson KL, Anderson SD, Ohama E, Reaume AG, Scott RW, Cleveland DW (1998) Aggregation and motor neuron toxicity of an ALS-linked SOD1 mutant independent from wildtype SOD1. Science 281:851-854. Medline

Buchberger A, Bukau B, Sommer T (2010) Protein quality control in the cytosol and the endoplasmic reticulum: brothers in arms. Mol Cell 40: 238-252. CrossRef Medline

Calixto A, Chelur D, Topalidou I, Chen X, Chalfie M (2010) Enhanced neuronal RNAi in C. elegans using SID-1. Nat Methods 7:554-559. CrossRef Medline

Chen L, Madura K (2002) Rad23 promotes the targeting of proteolytic substrates to the proteasome. Mol Cell Biol 22:4902-4913. CrossRef Medline

Chen L, Madura K (2006) Evidence for distinct functions for human DNA repair factors hHR23A and hHR23B. FEBS Lett 580:3401-3408. CrossRef Medline

Chen L, Shinde U, Ortolan TG, Madura K (2001) Ubiquitin-associated (UBA) domains in $\operatorname{Rad} 23$ bind ubiquitin and promote inhibition of multi-ubiquitin chain assembly. EMBO Rep 10:933-938. CrossRef Medline

Chiang PM, Ling J, Jeong YH, Price DL, Aja SM, Wong PC (2010) Deletion of TDP-43 down-regulates Tbc1d1, a gene linked to obesity, and alters body fat metabolism. Proc Natl Acad Sci U S A 107:16320-16324. CrossRef Medline

Cirulli ET, Lasseigne BN, Petrovski S, Sapp PC, Dion PA, Leblond CS, Couthouis J, Lu YF, Wang Q, Krueger BJ, Ren Z, Keebler J, Han Y, Levy SE, Boone BE, Wimbish JR, Waite LL, Jones AL, Carulli JP, Day-Williams AG, et al. (2015) Exome sequencing in amyotrophic lateral sclerosis identifies risk genes and pathways. Science 347:1436-1441. CrossRef Medline

Cleveland DW, Rothstein JD (2001) From Charcot to Lou Gehrig: deciphering selective motor neuron death in ALS. Nat Rev Neurosci 2:806819. CrossRef Medline

Cronin S, Hardiman O, Traynor BJ (2007) Ethnic variation in the incidence of ALS: a systematic review. Neurology 68:1002-1007. CrossRef Medline

Dangond F, Hwang D, Camelo S, Pasinelli P, Frosch MP, Stephanopoulos G, Stephanopoulos G, Brown RH, and Gullans SR (2004) Molecular signature of late-stage human ALS revealed by expression profiling of postmortem spinal cord gray matter. Physiol Genomics 16:229-239. Medline

Dantuma NP, Heinen C, Hoogstraten D (2009) The ubiquitin receptor RAD-23: at the crossroads of nuclear excision repair and proteasomal degradation. DNA Repair 8:449-460. CrossRef Medline

Deng HX, Shi Y, Furukawa Y, Zhai H, Fu R, Liu E, Gorrie GH, Khan MS, Hung WY, Bigio EH, Lukas T, Dal Canto MC, O’Halloran TV, Siddique T (2006) Conversion to the amyotrophic lateral sclerosis phenotype is associated with intermolecular linked insoluble aggregates of SOD1 in mitochondria. Proc Natl Acad Sci U S A 103:7142-7147. CrossRef Medline

Deng HX, Chen W, Hong ST, Boycott KM, Gorrie GH, Siddique N, Yang Y, Fecto F, Shi Y, Zhai H, Jiang H, Hirano M, Rampersaud E, Jansen GH, Donkervoort S, Bigio EH, Brooks BR, Ajroud K, Sufit RL, Haines JL, et al. (2011) Mutations in UBQLN2 cause dominant X-linked juvenile and adult-onset ALS and ALS/dementia. Nature 477:211-215. CrossRef Medline

Fawzi NL, Yap EH, Okabe Y, Kohlstedt KL, Brown SP, Head-Gordon T (2008) Contrasting disease and nondisease protein aggregation by molecular simulation. Acc Chem Res 41:1037-1047. CrossRef Medline

Filézac de L'Etang A, Maharjan N, Cordeiro BrañaMC, Ruegsegger C, Rehmann R, Goswami A Roos A, Troost D, Schneider BL, Weis J, Saxena S (2015) Marinesco-Sjögren syndrome protein SIL1 regulates motor neuron subtype-selective ER stress in ALS. Nat Neurosci 18:227-238. CrossRef Medline

Fraser AG, Kamath RS, Zipperlen P, Martinez-Campos M, Sohrmann M, Ahringer J (2000) Functional genomic analysis of C. elegans chromosome I by systematic RNA interference. Nature 408:325-330. CrossRef Medline Gennarino VA, Singh RK, White JJ, De Maio A, Han K, Kim JY, Jafar-Nejad P, di Ronza A, Kang H, Sayegh LS, Cooper TA, Orr HT, Sillitoe RV, Zoghbi HY (2015) Pumiliol haploinsufficiency leads to SCA1-like neurodegeneration by increasing wild-type ataxin1 levels. Cell 160:1087-1098. CrossRef Medline

Graffmo KS, Forsberg K, Bergh J, Birve A, Zetterström P, Andersen PM, Marklund SL, Brännström T (2013) Expression of wild-type human superoxide dismutase- 1 in mice causes amyotrophic lateral sclerosis. Hum Mol Genet 22:51-60. CrossRef Medline

Habibi-Babadi N, Su A, de Carvalho CE, Colavita A (2010) The N-glycanase png- 1 acts to limit axon branching during organ formation in Caenorhabditis elegans. J Neurosci 30:1766-1776. CrossRef Medline

Jaarsma D, Haasdijk ED, Grashorn JA, Hawkins R, van Duijn W, Verspaget HW, London J, Holstege JC (2000) Human Cu/Zn superoxide dismutase (SOD1) overexpression in mice causes mitochondrial vacuolization, axonal degeneration, and premature motoneuron death and accelerates motoneuron disease in mice expressing a familial amyotrophic lateral sclerosis mutant SOD1. Neurobiol Dis 7:623-643. CrossRef Medline

Jaarsma D, van der Pluijm I, de Waard MC, Haasdijk ED, Brandt R, Vermeij M, Rijksen Y, Maas A,van Steeg H, Hoeijmakers JH, van der Horst GT (2011) Age-related neuronal degeneration: complementary roles of nucleotide excision repair and transcription-coupled repair in preventing neuropathology. PLoS Genet 7:e1002405. CrossRef Medline

Johnson ES, Ma PC, Ota IM, Varshavsky A (1995) A proteolytic pathway that recognizes ubiquitin as a degradation signal. J Biol Chem 270:1744217456. CrossRef Medline 
Johnson JO, Mandrioli J, Benatar M, Abramzon Y, Van Deerlin VM, Trojanowski JQ, Gibbs JR, Brunetti M, Gronka S, Wuu J, Ding J, McCluskey L, Martinez-Lage M, Falcone D, Hernandez DG, Arepalli S, Chong S, Schymick JC, Rothstein J, Landi F, et al. (2010) Exome sequencing reveals VCP mutations as a cause of familial ALS. Neuron 68:857-864. CrossRef Medline

Kikuchi H, Almer G, Yamashita S, Guégan C, Nagai M, Xu Z, Sosunov AA, McKhann GM 2nd, Przedborski S (2006) Spinal cord endoplasmic reticulum stress associated with a microsomal accumulation of mutant superoxide dismutase-1 in an ALS model. Proc Natal Acad Sci U S A 103: 6025-6030. CrossRef Medline

Kim I, Mi K, Rao H (2004) Multiple interactions of rad23 suggest a mechanism for ubiquitylated substrate delivery important in proteolysis. Mol Biol Cell 15:3357-3365. CrossRef Medline

Krajacic P, Shen X, Purohit PK, Arratia P, Lamitina T (2012) Biomechanical profiling of Caenorhabditis elegans. Genetics 191:1015-1021. CrossRef Medline

Lambertson D, Chen L, Madura K (1999) Pleiotropic defects caused by loss of the proteasome-interacting factors Rad 23 and Rpn 10 of Saccharomyces cerevisiae. Genetics 153:69-79. Medline

Lans H, Marteijn JA, Schumacher B, Hoeijmakers JH, Jansen G, Vermeulen W (2010) Involvement of global genome repair, transcription coupled repair, and chromatin remodeling in UV DNA damage response changes during development. PLoS Genet 6:e1000941. CrossRef Medline

Liachko NF, Guthrie CR, Kraemer BC (2010) Phosphorylation promotes neurotoxicity in a Caenorhabditis elegans model of TDP-43 proteinopathy. J Neurosci 30:16208-16219. CrossRef Medline

Lim MA, Selak MA, Xiang Z, Krainc D, Neve RL, Kraemer BC, Watts JL, Kalb RG (2012) Reduced activity of AMP-activated protein kinase protects against genetic models of motor neuron disease. J Neurosci 32:11231141. CrossRef Medline

Ling SC, Albuquerque CP, Han JS, Lagier-Tourenne C, Tokunaga S, Zhou H, Cleveland DW (2010) ALS-associated mutations in TDP-43 increase its stability and promote TDP-43 complexes with FUS/TLS. Proc Natl Acad Sci U S A 107:13318-13323. CrossRef Medline

Ling SC, Polymenidou M, Cleveland DW (2013) Converging mechanisms in ALS and FTD: disrupted RNA and protein homeostasis. Neuron 79: 416-438. CrossRef Medline

Lommel L, Ortolan T, Chen L, Madura K, Sweder KS (2002) Proteolysis of a nucleotide excision repair protein by the $26 \mathrm{~S}$ proteasome. Curr Genet 42:9-20. CrossRef Medline

Lu K, Psakhye I, Jentsch S (2014) Autophagic clearance of polyQ proteins mediated by ubiquitin-Atg8 adaptors of the conserved CUET protein family. Cell 158:549-563. CrossRef Medline

Madabhushi R, Pan L, Tsai LH (2014) DNA damage and its links to neurodegeneration. Neuron 83:266-282. CrossRef Medline

Mojsilovic-Petrovic J, Jeong GB, Crocker A, Arneja A, David S, Russell D, Kalb RG (2006) Protecting motor neurons from toxic insult by antagonism of adenosine A2a and Trk receptors. J Neurosci 26:9250-9263. CrossRef Medline

Morreale G, Conforti L, Coadwell J, Wilbrey AL, Coleman MP (2009) Evolutionary divergence of valosin-containing protein/cell division cycle protein 48 binding interactions among endoplasmic reticulumassociated degradation. FEBS J 276:1208-1220. CrossRef Medline

Myers AJ, Gibbs JR, Webster JA, Rohrer K, Zhao A, Marlowe L, Kaleem M, Leung D, Bryden L, Nath P, Zismann VL, Joshipura K, Huentelman MJ, Hu-Lince D, Coon KD, Craig DW, Pearson JV, Holmans P, Heward CB, Reiman EM, et al. (2007) A survey of genetic human cortical gene expression. Nat Genet 39:1494-1499. CrossRef Medline

Nagata T, Ilieva H, Murakami T, Shiote M, Narai H, Ohta Y, Hayashi T, Shoji M, Abe K (2007) Increased ER stress during motor neuron degeneration in transgenic mouse model of amyotrophic lateral sclerosis. Neurol Res 29:767-771. CrossRef Medline

Neumann M, Kwong LK, Lee EB, Kremmer E, Flatley A, Xu Y, Forman MS, Troost D, Kretzschmar HA, Trojanowski JQ, Lee VM (2009) Phosphorylation of S409/410 of TDP-43 is a consistent feature in all sporadic and familial forms of TDP-43 proteinopathies. Acta Neuropathol 117:137149. CrossRef Medline

Neve RL, Howe JR, Hong S, Kalb RG (1997) Introduction of the glutamate receptor subunit 1 into motor neurons in vitro and in vivo using a recombinant herpes simplex virus. Neuroscience 79:435-447. CrossRef Medline
New M, Olzscha H, Liu G, Khan O, Stimson L, McGouran J, Kerr D, Coutts A, Kessler B, Middleton M, La Thangue NB (2013) A regulatory circuit that involves HR23B and HDAC6 governs the biological response to HDAC inhibitors. Cell Death Differ 20:1306-1316. CrossRef Medline

Ng JM, Veremeulen W, van der Horst GTJ, Bergink S, Sugasawa K, Vrieling H, Hoeijmakers JHJ (2003) A novel regulation mechanism of DNA repair by damage-induced and RAD-23-dependent stabilization of xeroderma pigmentosum group C protein. Genes Dev 17:1640-1645. CrossRef Medline

Nishitoh H, Kadowaki H, Nagai A, Maruyama T, Yokota T, Fukutomi H, Noguchi T, Matsuzawa A, Takeda K, Ichijo H (2008) ALS-linked mutant SOD1 induces ER stress and ASK1-dependent motor neuron death by targeting Derlin-1. Genes Dev 22:1451-1464. CrossRef Medline

Okuda Y, Nishi R, Ng JM, Vermeulen W, van der Horst GT, Mori T, Hoeijmakers JH, Hanaoka F, Sugasawa K (2004) Relative levels of the two mammalian RAD-23 homologs determine composition and stabilization of xeroderma pigmentosum group C protein complex. DNA Repair (Amst.) 3:1285-1295.

Ortolan TG, Tongaonkar P, Lambertson D, Chen L, Schauber C,Madura K (2000) The Rad23 DNA repair protein is a negative regulator of substrate-linked multi-ubiquitin chain assembly. Nat Cell Biol 2:601608. CrossRef Medline

Ortolan TG, Chen L, Tongaonkar P, Madura K (2004) Rad23 stabilizes Rad4 from degradation by the Ub/proteasome pathway. Nucleic Acids Res 32:6490-6500. CrossRef Medline

Periz G, Lu J, Zhang T, Kankel MW, Jablonski AM, Kalb R, McCampbell A, Wang J (2015) Regulation of protein quality control by UBE4B and LSD1 through p53-mediated transcription. PloS Biolgy 13: e1002114. CrossRef Medline

Polymenidou M, Lagier-Tourenne C, Hutt KR, Huelga SC, Moran J, Liang TY, Ling SC, Sun E, Wancewicz E, Mazur C, Kordasiewicz H, Sedaghat Y, Donohue JP, Shiue L, Bennett CF, Yeo GW, Cleveland DW (2011) Long pre-mRNA depletion and RNA missplicing contribute to neuronal vulnerability from loss of TDP-43. Nat Neurosci 14:459-468. CrossRef Medline

Prakash S, Sung P, Prakash L (1993) DNA repair genes and proteins of Saccharomyces cerevisiae. Annu Rev Genet 27:33-70. CrossRef Medline

Raasi S, Pickart CM (2003) Rad23 ubiquitin-associated domains (UBA) inhibit $26 \mathrm{~S}$ proteasome-catalyzed proteolysis by sequestering lysine 48 linked polyubiquitin chains. J Biol Chem 278:1-9. CrossRef Medline

Rao H, Sastry A (2002) Recognition of specific ubiquitin conjugates is important for proteolytic functions of the ubiquitin-associated domain proteins Dsk2 and Rad23. J Biol Chem 277:11691-11695. CrossRef Medline

Rothstein JD (2009) Current hypotheses for the underlying biology of amyotrophic lateral sclerosis. Ann Neurol 65 [Suppl 1]:S3-S9.

Rumpf S, Jentsch S (2006) Functional division of substrate processing cofactors of the ubiquitin-selective Cdc48 chaperone. Mol Cell 21:261-269. CrossRef Medline

Ryu KS, Lee KJ, Bae SH, Kim BK, Kim KA, Choi BS (2003) Binding surface mapping of intra- and interdomain interactions among hHR23B, ubiquitin, and polyubiquitin binding site 2 of S5a. J Biol Chem 278:3662136627. CrossRef Medline

Saxena S, Cabuy E, Caroni P (2009) A role for motoneuron subtypeselective ER stress in disease manifestations of FALS mice. Nat Neurosci 12:627-636. CrossRef Medline

Schauber C, Chen L, Tongaonkar P, Vega I, Lambertson D, Potts W, Madura K (1998) RAD-23 links DNA repair to the ubiquitin/proteasome pathway. Nature 391:715-718. CrossRef Medline

Scotter EL, Vance C, Nishimura AL, Lee YB, Chen HJ, Urwin H, Sardone V, Mitchell JC, Rogelj B, Rubinsztein DC, Shaw CE (2014) Differential roles of the ubiquitin proteasome system (UPS) and autophagy in the clearance of aggregated TDP-43 species. J Cell Sci 127:1263-1278. CrossRef Medline

Sznitman R, Gupta M, Hager GD, Arratia PE, Sznitman J (2010) Multienvironment model estimation for motility analysis of Caenorhabditis elegans. PLoS One 5:e11631. CrossRef Medline

Thompson ML, Chen P, Yan X, Kim H, Borom AR, Roberts NB, Caldwell KA, Caldwell GA (2014) TorsinA rescues ER-associated stress and locomotive defects in C. elegans models of ALS. Dis Model Mech 7:233-243. CrossRef Medline

Vaccaro A, Patten SA, Aggad D, Julien C, Maios C, Kabashi E, Drapeau P, Parker JA (2013) Pharmacological reduction of ER stress protects 
against TDP-43 neuronal toxicity in vivo. Neurobiol Dis 55:64-75. CrossRef Medline

van Laar T, van der Eb AJ, Terleth C (2002) A role for Rad-23 proteins in $26 \mathrm{~S}$ proteasome-dependent protein degradation? Mutat Res 499:53-61. CrossRef Medline

Vembar SS, Brodsky JL (2008) One step at a time: endoplasmic reticulumassociated degradation. Nat Rev Mol Cell Biol 9:944-957. CrossRef Medline

Verma R, Oania R, Graumann J, Deshaies RJ (2004) Multiubiquitin chain receptors define a layer of substrate selectivity in the ubiquitinproteasome system. Cell 118:99-110. CrossRef Medline

Walker AK, Soo KY, Sundaramoorthy V, Parakh S, Ma Y, Farg MA, Wallace RH, Crouch PJ, Turner BJ, Horne MK, Atkin JD (2013) ALS-associated TDP-43 induced endoplasmic reticulum stress, which drives cytoplasmic TDP-43 accumulation and stress granule formation. PLoS One 8:e81170. CrossRef Medline

Wang J, Farr GW, Hall DH, Li F, Furtak K, Dreier L, Horwich AL (2009) An ALS-linked mutant SOD1 produces a locomotor defect associated with aggregation and synapse dysfunction when expressed in neurons of Caenorhabditis elegans. PLoS Genet 5: e1000350. CrossRef Medline

Wang L, Deng HX, Grisotti G, Zhai H, Siddique T, Roos RP (2009) Wildtype SOD1 overexpression accelerates disease onset of a G85R SOD1 mouse. Hum Mol Genet 18:1642-1651. CrossRef Medline

Wang L, Popko B, Roos RP (2011) The unfolded protein response in familial amyotrophic lateral sclerosis. Hum Mol Genet 20:1008-1015. CrossRef Medline

Watkins JF, Sung P, Prakash L, Prakash S (1993) The Saccharomyces cerevisiae DNA repair gene RAD23 encodes a nuclear protein containing a ubiquitin-like domain required for biological function. Mol Cell Biol 13:7757-7765. CrossRef Medline

Wegorzewska I, Bell S, Cairns NJ, Miller TM, Baloh RH (2009) TDP-43 mutant transgenic mice develop features of ALS and frontotemporal lo- bar degeneration. Proc Natl Acad Sci U S A 106:18809-18814. CrossRef Medline

Wilkinson CR, Seeger M, Hartmann-Petersen R, Stone M, Wallace M, Semple C, Gordon C (2001) Proteins containing the UBA domain are able to bind to multi-ubiquitin chains. Nat Cell Biol 3:939-943. CrossRef Medline

Wils H, Kleinberger G, Janssens J, Pereson S, Joris G, Cuijt I, Smits V, Ceuterick-de Groote C, Van Broeckhoven C, Kumar-Singh S (2010) TDP-43 transgenic mice develop spastic paralysis and neuronal inclusions characteristic of ALS and frontotemporal lobar degeneration. Proc Natl Acad Sci U S A 107:3858-3863. CrossRef Medline

Wong YC, Holzbaur EL (2014) Optineurin is an autophagy receptor for damaged mitochondria in parkin-mediated mitophagy that is disrupted by an ALS-linked mutation. Proc Natl Acad Sci U S A 111:E4439-E4448. CrossRef Medline

Xu YF, Gendron TF, Zhang YJ, Lin WL, D'Alton S, Sheng H, Casey MC, Tong J, Knight J, Yu X, Rademakers R, Boylan K, Hutton M, McGowan E, Dickson DW, Lewis J, Petrucelli L (2010) Wild-type human TDP-43 expression causes TDP-43 phosphorylation, mitochondrial aggregation, motor deficits, and early mortality in transgenic mice. J Neurosci 30 : 10851-10859. CrossRef Medline

Xu YF, Zhang YJ, Lin WL, Cao X, Stetler C, Dickson DW, Lewis J, Petrucelli L (2011) Expression of mutant TDP-43 induces neuronal dysfunction in transgenic mice. Mol Neurodegener 6:73. CrossRef Medline

Yokoi M, Masutani C, Maekawa T, Sugasawa K, Ohkuma Y and Hanaoka F (2000) The xeroderma pigmentosum group C protein complex XPCHR23B plays an important role in the recruitment of transcription factor IIH to damaged DNA. J Biol Chem 275:9870-9875. CrossRef Medline

Zhong X, Pittman RN (2006) Ataxin-3 binds VCP/p97 and regulates retrotranslocation of ERAD substrates. Hum Mol Genet 15:2409-2420. CrossRef Medline 